\title{
The effects of perfluorocarbon dosing strategy on cerebral blood flow when starting partial liquid ventilation: $A$ randomised, controlled, experimental study
}

\author{
Mark W. Davies ${ }^{1,2,3}$, Kimble R. Dunster ${ }^{1,4,5}$, John F. Fraser ${ }^{2,5}$, Paul B. Colditz \\ ${ }^{1}$ Grantley Stable Neonatal Unit, Royal Brisbane and Women's Hospital, Brisbane, Australia \\ ${ }^{2}$ Department of Paediatrics \& Child Health, The University of Queensland, Brisbane, Australia \\ ${ }^{3}$ Perinatal Research Centre, The University of Queensland, Royal Brisbane and Women's Hospital, Brisbane, Australia \\ ${ }^{4}$ Medical Engineering Research Facility, Queensland University of Technology, Brisbane, Australia \\ ${ }^{5}$ Critical Care Research Group, The Prince Charles Hospital, Brisbane, Australia \\ Email: Mark_Davies@health.qld.gov.au
}

Received 14 May 2012; revised 16 July 2012; accepted 25 July 2012

\begin{abstract}
Introduction: Partial liquid ventilation may benefit the lung disease in preterm neonates but intratracheal instillation of perfluorocarbon increases cerebral blood flow and may cause brain injury. We aimed to determine if the effects of perfluorocarbon administration on cerebral blood flow vary by dose-volume, rate of administration, endotracheal tube portal of entry, or closely targeting $\mathrm{PaCO}_{2}$. Methods: Forty-two dosing events (in eleven rabbits) were randomised to different dosing strategies, including a sham (i.e., placebo/control) dose of air over $20 \mathrm{~min}, 20 \mathrm{~mL} / \mathrm{kg}$ of perfluorocarbon slowly over $20 \mathrm{~min}, 10 \mathrm{~mL} / \mathrm{kg}$ of perfluorocarbon slowly over $20 \mathrm{~min}, 10 \mathrm{~mL} / \mathrm{kg}$ of perfluorocarbon moderately fast over $10 \mathrm{~min}, 10 \mathrm{~mL} / \mathrm{kg}$ of perfluorocarbon rapidly over $5 \mathrm{~min}, 10 \mathrm{~mL} / \mathrm{kg}$ of perfluorocarbon slowly over $20 \mathrm{~min}$ via the endotracheal tube tip lumen (as opposed to the proximal end of the tube used in all other groups), or $10 \mathrm{~mL} / \mathrm{kg}$ of perfluorocarbon slowly over 20 min whilst targeting a $\mathrm{PaCO}_{2}$ of 45 - $50 \mathrm{mmHg}$. Blood gases, haemodynamics, cortical cerebral blood flow and carotid flow were recorded continuously for $\mathbf{3 0}$ minutes from the start of each dose. Results: Carotid flow increased with $20 \mathrm{~mL} / \mathrm{kg}$ perfluorocarbon and cortical cerebral blood flow was significantly more variable. Carotid and cortical cerebral blood flow increased using 10 $\mathrm{mL} / \mathrm{kg}$ or $20 \mathrm{~mL} / \mathrm{kg}$ with no difference between the two dose-volumes. There was no difference in cerebral blood flow by rate of administration, but carotid blood flow was more variable during slow administration. There were no differences in the increase in cerebral blood flow by portal of entry. If $\mathrm{PaCO}_{2}$ was maintained between $45-50 \mathrm{mmHg}$ there was no increase in cerebral blood flow and there was less variable
\end{abstract}

carotid flow. Conclusions: Cerebral blood flow increases with perfluorocarbon dosing. This occurs regardless of the dose-volume of perfluorocarbon. These effects were mitigated by closely targeting $\mathrm{PaCO}_{2}$.

Keywords: Cerebral Blood Flow; Fluorocarbons; Infant; Newborn Preterm; Partial Liquid Ventilation

\section{INTRODUCTION}

Preterm infants, especially those born extremely preterm, require a great deal of support ex utero. They are often severely ill and their chances of survival are greatly reduced [1]. Many die because of general immaturity; as multiple organ systems, including the lungs, cannot adapt to extrauterine life. Many die of overt lung disease [1]. However, the positive pressure ventilation which they require to survive is often a cause of significant and persistent lung injury [2].

Partial liquid ventilation has been touted as an alternative form of respiratory support for extremely immature lungs and severe lung disease: not only to provide a more effective form of respiratory support but to provide that support with much less lung injury [3]. A recent experimental study has renewed the promise that partial liquid ventilation has significant potential to alter the course of neonatal lung disease and reduce respiratory morbidity [4].

Extremely preterm infants are also prone to specific forms of brain injury such as intraventricular haemorrhage, periventricular leucomalacia and other types of white matter injury [5]. Rapid changes or disturbance of ventilation can lead to fluctuations in cerebral blood flow which have been shown to substantially increase the risk of brain injury [6,7]. 
In a previous study we have shown that preterm lambs receiving a $30 \mathrm{~mL} / \mathrm{kg}$ dose of tracheal perfluorocarbon liquid, given over 20 minutes at the start of partial liquid ventilation, had an increased cortical cerebral blood flow [8]. This did not seem to be due to any general haemodynamic disturbance, although the lambs that had tracheal perfluorocarbon did have a small, non-significant increase in arterial carbon dioxide [8]. The increase in cortical cerebral blood flow did not differ with varying doses of tracheal perfluorocarbon $(20,30$ or $40 \mathrm{~mL} / \mathrm{kg}$ given over 20 minutes) [9].

As with any treatment, the benefits of partial liquid ventilation will need to be weighed against any harm. It is known that increases in cerebral blood flow put very preterm infants at greater risk of intraventricular haemorrhage and brain injury [6,7]. Any gains in using partial liquid ventilation to improve gas exchange should not be at the expense of a higher risk of brain injury. It may be that smaller doses of perfluorocarbon will allow adequate treatment of lung disease with minimal effects on cerebral blood flow. Also, regardless of the dose used, it may be that perfluorocarbon dosing can be optimised to minimise any effects on cerebral blood flow.

Before its use in human preterm neonates, the effects on cerebral blood flow of partial liquid ventilation need to be determined in a relevant animal model. It has not been established whether different methods of giving the initial dose of perfluorocarbon affect the degree and duration of any changes in cerebral blood flow.

We hypothesised that a $20 \mathrm{~mL} / \mathrm{kg}$ dose of perfluorocarbon administered when starting partial liquid ventilation would disturb cerebral blood flow. Liquid ventilation starts when the perfluorocarbon liquid is introduced into the lungs. We also hypothesised that the degree and duration of changes in cerebral blood flow would vary with:

- the dose of perfluorocarbon administered;

- the duration over which the dose is given $(5,10$ or 20 minutes);

- the portal of entry of the perfluorocarbon into the ETT (side-port on the ETT manifold versus an auxiliary lumen further down the ETT); and

- whether, during pressure-controlled ventilation, the peak inspiratory pressure is adjusted to maintain $\mathrm{PaCO}_{2}$ or not.

Our aims were to:

1) confirm in a rabbit model (with no lung disease) that administration of a dose of $20 \mathrm{~mL} / \mathrm{kg}$ of perfluorocarbon during commencement of partial liquid ventilation increased cerebral blood flow and its variability;

2) investigate the effects of a lower initial dose (10 $\mathrm{mL} / \mathrm{kg}$ versus $20 \mathrm{~mL} / \mathrm{kg}$ ) of perfluorocarbon on cerebral blood flow and its variability;

3) investigate the effects of different rates of ad- ministration of the initial dose of perfluorocarbon (10 $\mathrm{mL} / \mathrm{kg}$ over 5,10 or 20 minutes) on cerebral blood flow and its variability;

4) investigate the effects of the ETT portal of entry of the initial dose of perfluorocarbon on cerebral blood flow and its variability;

5) investigate the effects of adjusting the peak inspiratory pressure to maintain the arterial carbon dioxide between 45 and $50 \mathrm{mmHg}$ during the initial dose of perfluorocarbon on cerebral blood flow and its variability.

\section{MATERIALS AND METHODS}

To study the effects of different dosing strategies of perfluorocarbon, we used the adult New Zealand white rabbit which is in the human neonatal weight-range (similar to the preterm lambs previously studied $[8,9]$ ). The necessary procedures and monitoring are readily performed in rabbits of this size. The use of an adult rabbit with no lung disease allows repeated study over many hours.

\subsection{Animal Preparation}

Anaesthesia was induced in each rabbit with intramuscular atropine $(0.1 \mathrm{mg} / \mathrm{kg})$ followed by intra-muscular Zoletil (tiletamine and zolazepam, $10 \mathrm{mg} / \mathrm{kg}$ ) and xylazine $(2 \mathrm{mg} / \mathrm{kg})$. An intra-venous line (22 - 24 gauge Insyte catheter) was inserted into an ear vein and anaesthesia maintained with an infusion of propofol $(0.5 \mathrm{~mL} / \mathrm{kg} / \mathrm{hr})$. An intravenous infusion of $3 \mathrm{~mL} / \mathrm{kg} / \mathrm{hr}$ of $10 \%$ dextrose was given throughout. The rabbits were then intubated via a tracheostomy with a $3.0 \mathrm{HI}-\mathrm{LO}$ Jet multi-lumen endotracheal tube (MuLETT) [Mallinckrodt Inc, Argyle, New York, USA] with a ligature around the trachea (to prevent leakage). Mechanical ventilation was commenced as described below. Respiratory function was monitored with a VenTrak neonatal pneumotachograph and respiratory mechanics monitor (Model 1550, Novametrix Medical Systems, Wallingford, Connecticut, USA).

A NeoTrend catheter (Diametrics Medical, High Wycombe, UK), calibrated as per the manufacturer's instructions, was then inserted into the descending aorta via the femoral artery. This allowed continuous measurement of intra-arterial oxygen tension $\left(\mathrm{PaO}_{2}\right)$, carbon dioxide tension $\left(\mathrm{PaCO}_{2}\right), \mathrm{pH}$, temperature, bicarbonate, base excess and oxygen saturation.

The right common carotid artery was exposed and a 2 $\mathrm{mm}$ ultrasonic flow probe (Transonic 2SB) was placed around the right carotid artery and connected to the T206 Transonic Flowmeter (Transonic Systems Inc., Ithaca, New York, USA).

Cerebral cortical blood flow was monitored using a laser Doppler probe (Oxford Array, Oxford Optronix, Oxford, UK) inserted into the parietal cortex (through a 
burr hole half-way between a line joining the outer corner of the eye and top of the ear insertion, and the top of skull) and the probe was held in place as previously described [10].

Standard physiological monitoring included heart rate (ECG), oxygen saturation (peripheral pulse oximetry) and continuous arterial blood pressure.

After completion of all dosing events the rabbit was killed with $5 \mathrm{~mL}$ pentobarbitone sodium (Lethabarb, 325 $\mathrm{mg} / \mathrm{mL}$ ). The mean (SD) duration from anaesthesia induction to pentobarbitone injection was $7.7(0.74)$ hours.

\subsection{Mechanical Ventilation}

The rabbits were ventilated with a neonatal ventilator (Bear Cub, Bear Medical Systems, Riverside, California) at 30 breaths per minute, peak inspiratory pressure (PIP) $12 \mathrm{cmH}_{2} \mathrm{O}$, positive end expiratory pressure (PEEP) 5 $\mathrm{cmH}_{2} \mathrm{O}$, and inspiratory time of 0.75 seconds. The fraction of inspired oxygen $\left(\mathrm{FiO}_{2}\right)$ was initially 0.21 , increased as necessary to maintain pulse oximetry oxygen saturations between $94 \%$ and $97 \%$. PIP was adjusted to maintain $\mathrm{PaCO}_{2}$ between 40 - $45 \mathrm{mmHg}$ until the commencement of each dosing strategy phase. No further adjustment of ventilation, with the exception of $\mathrm{FiO}_{2}$, were allowed except during the PLV10-slow-proximal-PC-adjust PIP dosing strategy (see below).

\subsection{Perfluorocarbon Dose Volume}

The perfluorocarbon dose volumes were chosen to enable comparisons with earlier studies in preterm lambs. We chose $20 \mathrm{~mL} / \mathrm{kg}$, as used in our earlier preterm lamb studies [9], in order to confirm similar effects of perfluorocarbon dosing on cerebral blood flow. We then chose $10 \mathrm{~mL} / \mathrm{kg}$ as the comparison dose as it was more easily removed from the lungs between dosing events and yet was in the range of doses with demonstrated efficacy in animal studies. Dose-dependent improvement in lung function has been demonstrated during partial liquid ventilation but the majority of improvement in lung function has occurred with relatively small doses (up to $\sim 10 \mathrm{~mL} / \mathrm{kg}$ ) [11,12]. In rabbits $9-12 \mathrm{~mL} / \mathrm{kg}$ has been shown to improve lung function [12-14]. In animal models with no lung disease $10 \mathrm{~mL} / \mathrm{kg}$ has been shown to disturb gas exchange less than $30 \mathrm{~mL} / \mathrm{kg}$ and thus provide a more stable model to study haemodynamic effects [15].

\subsection{Group Allocation}

Each rabbit was allocated to multiple dosing strategies to reduce the number of animals used. Following preparation, each rabbit was randomly allocated a perfluorocarbon dosing strategy and then monitored for one minute before and 30 minutes after the start of each dosing event. After each dosing event (and washout period) each rabbit was randomly allocated to another perfluorocarbon dosing strategy.

Eleven rabbits (mean \pm SD weight of $4.0 \pm 0.59 \mathrm{~kg}$ ) were randomised to up to six of the seven following dosing strategies:

1) A CONTROL-PC group which was given a sham (i.e., placebo/control) dose of air $(10 \mathrm{~mL} / \mathrm{kg})$ over $20 \mathrm{~min}$ via the wye-piece at the proximal end of the ETT (see Figure 1) on pressure-controlled ventilation;

2) A PLV20-slow-proximal-PC group which was given $20 \mathrm{~mL} / \mathrm{kg}$ of FC-77 slowly over $20 \mathrm{~min}$ via the wyepiece at the proximal end of the ETT on pressure-controlled ventilation;

3) A PLV10-slow-proximal-PC group which was given $10 \mathrm{~mL} / \mathrm{kg}$ of FC-77 slowly over $20 \mathrm{~min}(0.5 \mathrm{~mL} / \mathrm{kg} / \mathrm{min})$ via the wye-piece at the proximal end of the ETT on pressure-controlled ventilation;

4) A PLV10-faster-proximal-PC group which was given $10 \mathrm{~mL} / \mathrm{kg}$ of FC-77 moderately fast over $10 \mathrm{~min}$ $(1.0 \mathrm{~mL} / \mathrm{kg} / \mathrm{min})$ via the wye-piece at the proximal end of the ETT on pressure-controlled ventilation;

5) A PLV10-rapid-proximal-PC group which was given $10 \mathrm{~mL} / \mathrm{kg}$ of FC-77 rapidly over $5 \mathrm{~min}(2.0 \mathrm{~mL} /$ $\mathrm{kg} / \mathrm{min}$ ) via the wye-piece at the proximal end of the ETT on pressure-controlled ventilation;

6) A PLV10-slow-tip-PC group which was given 10 $\mathrm{mL} / \mathrm{kg}$ of FC-77 slowly over $20 \mathrm{~min}$ via ETT tip lumen (see Figure 1) on pressure-controlled ventilation;

7) A PLV10-slow-proximal-PC-adjust PIP group which was given $10 \mathrm{~mL} / \mathrm{kg}$ of FC-77 slowly over $20 \mathrm{~min}$ via the wye-piece at the proximal end of the ETT with the PIP adjusted to maintain the $\mathrm{PaCO}_{2}$ between 45 and $50 \mathrm{mmHg}$ on pressure-controlled ventilation.

In groups 1 to 6 above no further adjustment of ventilation (with the exception of $\mathrm{FiO}_{2}$ ) was allowed after the commencement of each dosing event studied.

\section{Portal of Entry}

The dose of perfluorocarbon is usually given through a sideport wye-piece on the ETT-connector at the proximal end of the endotracheal tube. In this study doses of perfluorocarbon were given via one of two portals, either through a wye-piece at the proximal end of the ETT or through the ETT tip lumen (Figure 1). The use of a wye-piece was necessary to allow the pneumotachograph to be fitted between the ETT-circuit manifold and the ETT connector and prevent reflux of perfluorocarbon into the pneumotachograph during instillation.

\subsection{Washout}

Each dosing event was monitored for 30 minutes from the start of perfluorocarbon dosing. After each dosing 


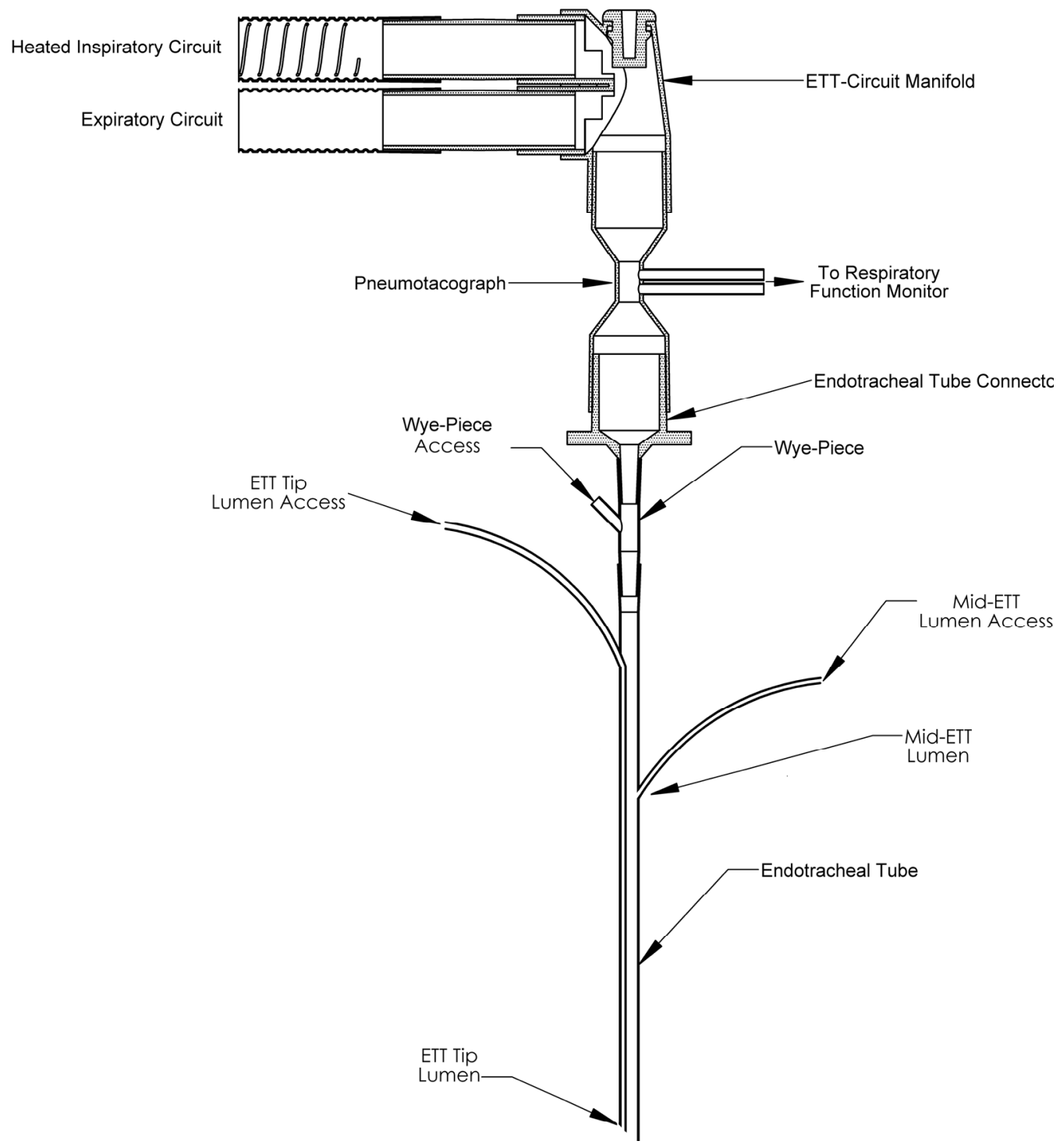

Figure 1. Configuration of the multi-lumen endotracheal tube (MuLETT), pneumotachograph, ETT connector, ETT circuit manifold and wye-piece.

event as much FC-77 as possible was sucked out of the ETT and trachea using a 5FG umbilical artery catheter and syringe. Any remaining FC-77 was then left to evaporate from the lungs via the expiratory line of the ventilator circuit. Tracheal gas insufflation at $2 \mathrm{~L} / \mathrm{min}$ via the distal ETT tip lumen was also used to increase the rate of evaporation.

The completeness of perfluorocarbon washout could be confirmed when the expired tidal volume equalled the inspired tidal volume. Because there is no expired gas in the inspiratory limb of the ventilator circuit and FC-77 vapour is known to affect tidal volume measurement with the VenTrak pneumotachograph [16] it was possible to determine that all the FC-77 had evaporated from the lung when the expired tidal volume equalled the inspired tidal volume (i.e., when there was no more perfluo- rocarbon vapour in the expired gases). The effect of FC-77 vapour has been well documented [16]. The measurement of tidal volumes in the range from 5 to $25 \mathrm{~mL}$ using the VenTrak pneumotachograph has coefficients of variation ranging from 0.008 to 0.04 without perfluorocarbon vapour and from 0.006 to 0.06 with perfluorocarbon vapour. The differences seen in TV measurement are more than $7 \%$.

After this washout period, between each dosing event, mechanical ventilation continued as before. Once the rabbit was stable they were then randomly allocated to another perfluorocarbon dosing strategy as above.

Stabilisation times before each dosing event differed between those dosing events where there was no prior perfluorocarbon use (therefore no washout was required) and those dosing events where a prior washout was 
required. The mean $(\mathrm{SD})$ stabilisation time for the former was 15.4 (6.96) minutes and for the latter was 64.9 (14.26) minutes.

\subsection{Measurements}

Two methods of assessing cerebral blood flow were used, both recorded continuously: cerebral cortical blood flow (laser Doppler flowmetry), as used in the previous preterm lamb studies; and right carotid blood flow (Transonic Flowmeter). Carotid flow was used to assess more global brain blood flow to ensure that previous effects seen were not restricted to the cerebral cortex. The coefficient of variation $(\mathrm{CV})$ for these two measurements were calculated to assess their variability.

The following were all recorded continuously: heart rate, blood pressure, peripheral oxygen saturation (pulse oximetry), $\mathrm{PaO}_{2}, \mathrm{PaCO}_{2}, \mathrm{pH}$, bicarbonate, base excess, arterial oxygen saturation, temperature, dynamic compliance, peak inspiratory pressure, and tidal volume. $\mathrm{FiO}_{2}$ was recorded at the start of each dosing event and the timing of any changes recorded thereafter.

\subsection{Sample Size}

Sample size calculation was based on carotid blood flow data from Takeuchi et al. [17] where mean (SD) carotid blood flow was 13.8 (3.39) $\mathrm{mL} / \mathrm{min}$. Therefore a sample size of six in each group is required to show an absolute difference of $6.1 \mathrm{~mL} / \mathrm{min}$ between groups $(\alpha=0.05$, power of $80 \%-\beta=0.2$ ).

\subsection{Data Analysis}

\subsubsection{Data Display}

For each dosing event mean values for continuously measured variables and calculated variables were calculated at baseline (the average during the minute immediately prior to perfluorocarbon or air dosing) and every minute for the 30 minute observation period. For each 1 -min period means were calculated from all measurements made over the one minute period. For the six dosing events for each dosing strategy the mean (SD) was calculated at baseline and every minute to 30 minutes and these data were then displayed graphically over time. For laser Doppler flow and carotid blood flow the percent change from baseline was calculated for each datum and then for each dosing event the data were averaged for each one minute period. Calculations and graphs were produced using Microsoft Excel 2002 (Microsoft Corporation, Redmond, Washington, USA).

To assess the variability of laser Doppler flow and carotid flow, the coefficient of variation was calculated for each one minute period for each dosing event. The coefficient of variation is calculated by dividing the standard deviation by the mean for each one minute period.

\subsubsection{Statistical Analysis}

To determine if there were any statistically significant differences between the dosing strategy groups, the data were compared at two time points: at the end of the dosing period (i.e., at 5, 10 or $20 \mathrm{~min}$ ) and at the point of maximal difference between groups. These time points were chosen as the most clinically relevant points for between group comparisons. For the purpose of these statistical tests the data were converted to change from baseline - this controlled for any differences between dosing strategy groups at baseline. If the data were normally distributed and the variances were equal the groups were compared using Student's t-test or one-way ANOVA. If the data were not normally distributed or the variances were not equal the groups were compared using the Mann-Whitney test or Kruskal-Wallis test. The distribution of data were tested using the Kolmogorov-Smirnov normality test with Dallal-WilkinsonLillie for $\mathrm{P}$ value. The $\mathrm{F}$ test was used to compare variances. These data analyses were done using GraphPad Prism version 4.03 (GraphPad Software Inc., San Diego, CA). A p value of $<0.05$ was considered to be statisticcally significant.

\subsection{Ethics Approval}

Ethical approval was obtained from the University of Queensland Animal Experimentation and Ethics Committee. All of the experimental procedures were performed in accordance with the guidelines established by the National Health and Medical Research Council of Australia in its Australian Code of Practice for the Care and Use of Animals for Scientific Purposes [18].

\section{RESULTS}

Figures 2 and 3 show the relative changes (\% change from baseline) for both carotid flow and cortical cerebral blood flow for each perfluorocarbon dosing strategy. In each figure the vertical scales are identical for ease of comparison. Tables $\mathbf{1}$ and $\mathbf{2}$ summarise the maximum variations in flow for the two cerebral blood flow variables by dosing strategy.

\subsection{Does $20 \mathrm{~mL} / \mathrm{kg}$ of Perfluorocarbon Disturb Cerebral Blood Flow?}

We compared the CONTROL-PC group with the PLV20-slow-proximal-PC group.

Carotid blood flow was increased relative to baseline during the initial 20 minute dose of $20 \mathrm{~mL} / \mathrm{kg}$ perfluorocarbon when starting partial liquid ventilation compared with continuing on pressure-controlled conventional mechanical ventilation-Mann-Whitney test $\mathbf{p}=\mathbf{0 . 0 4}$ at the end of the dose and $p=0.04$ at the time of maximum difference $(21 \mathrm{~min})$. The highest mean increase in 


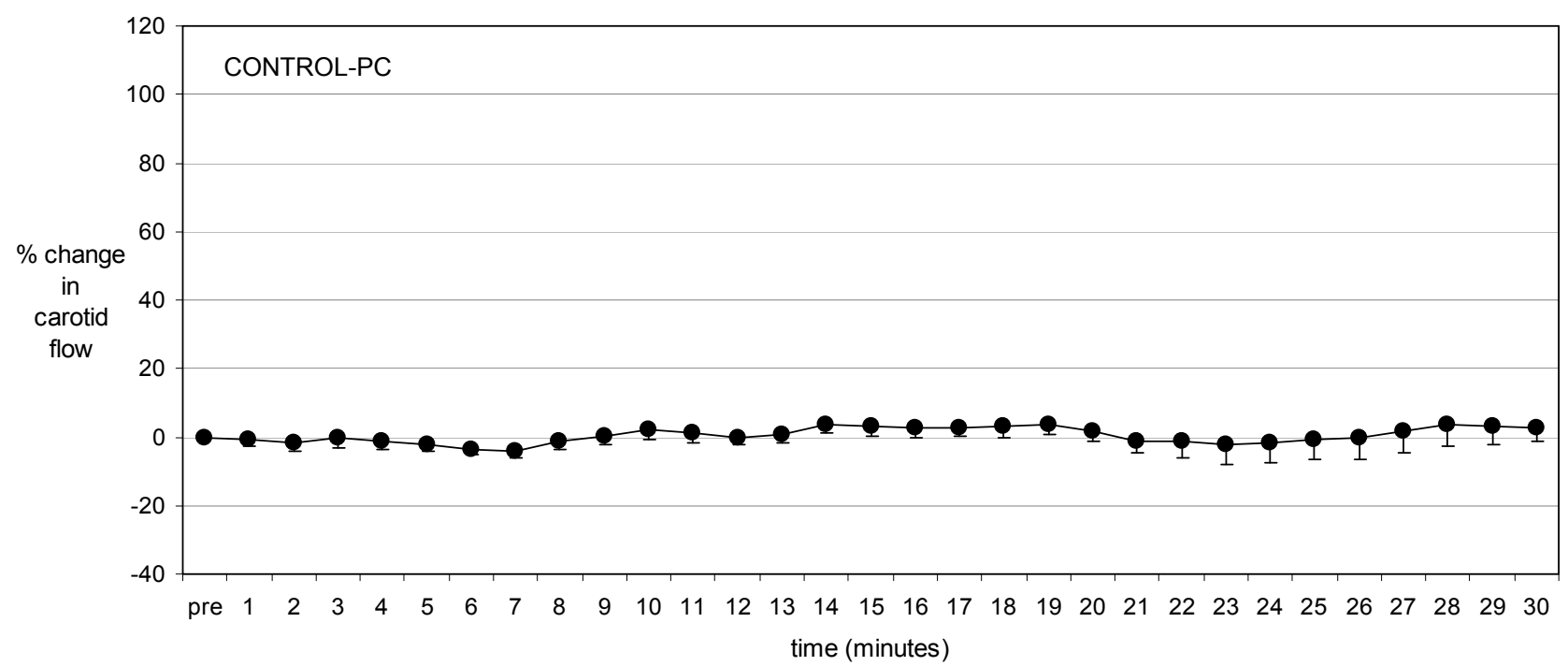

(a)

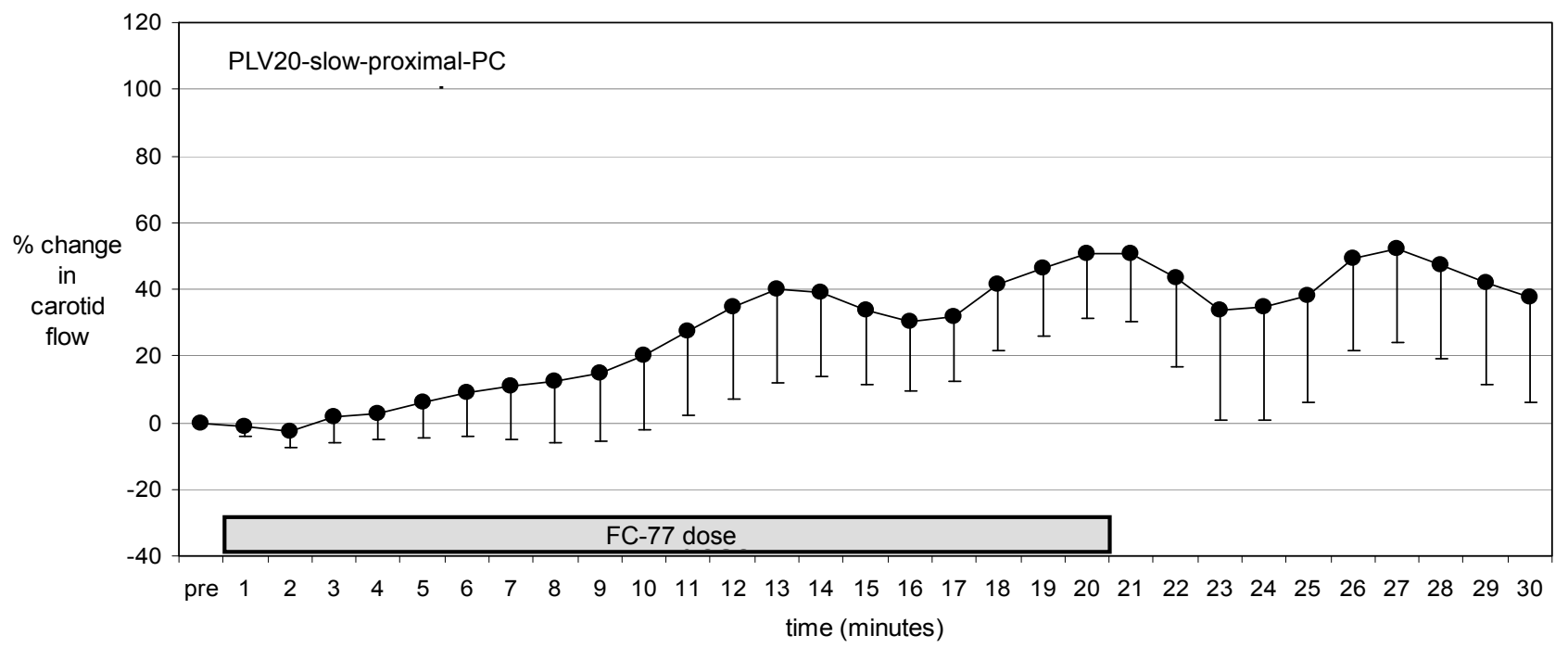

(b)

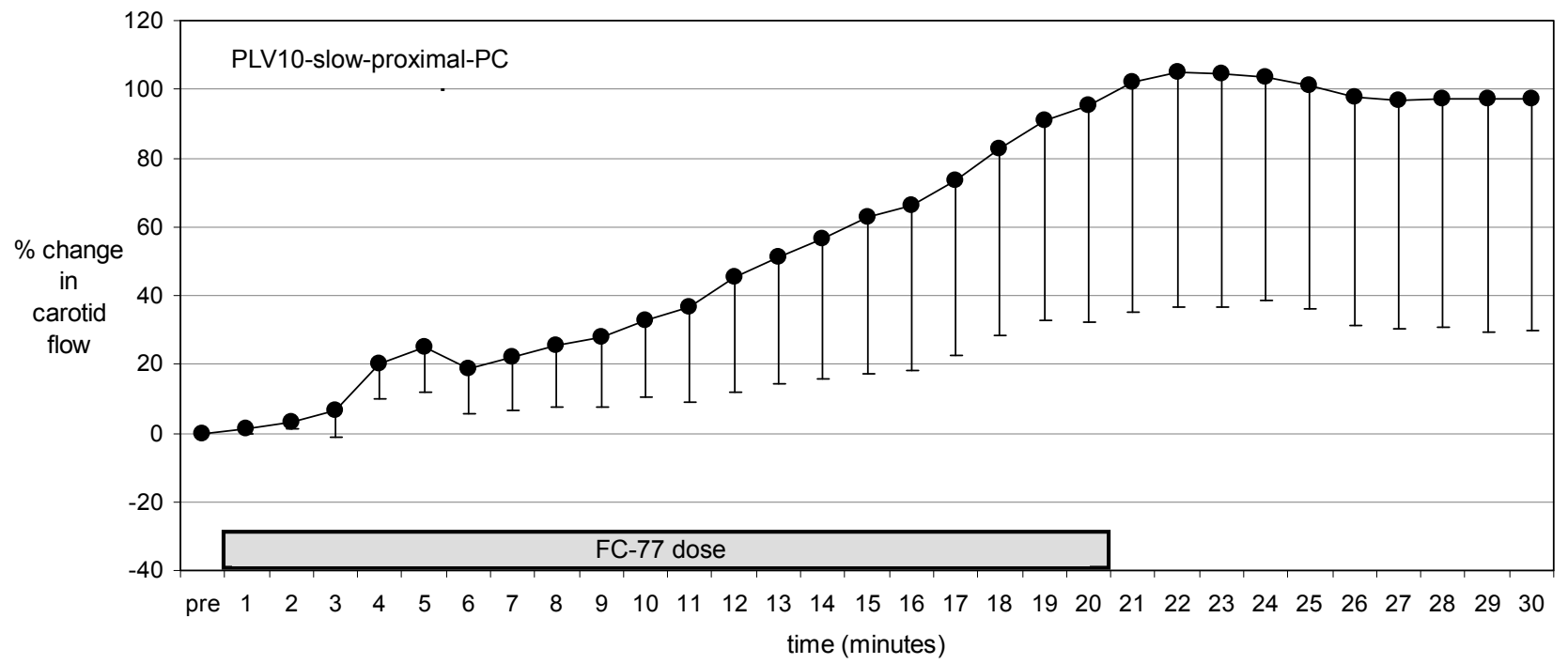

(c) 


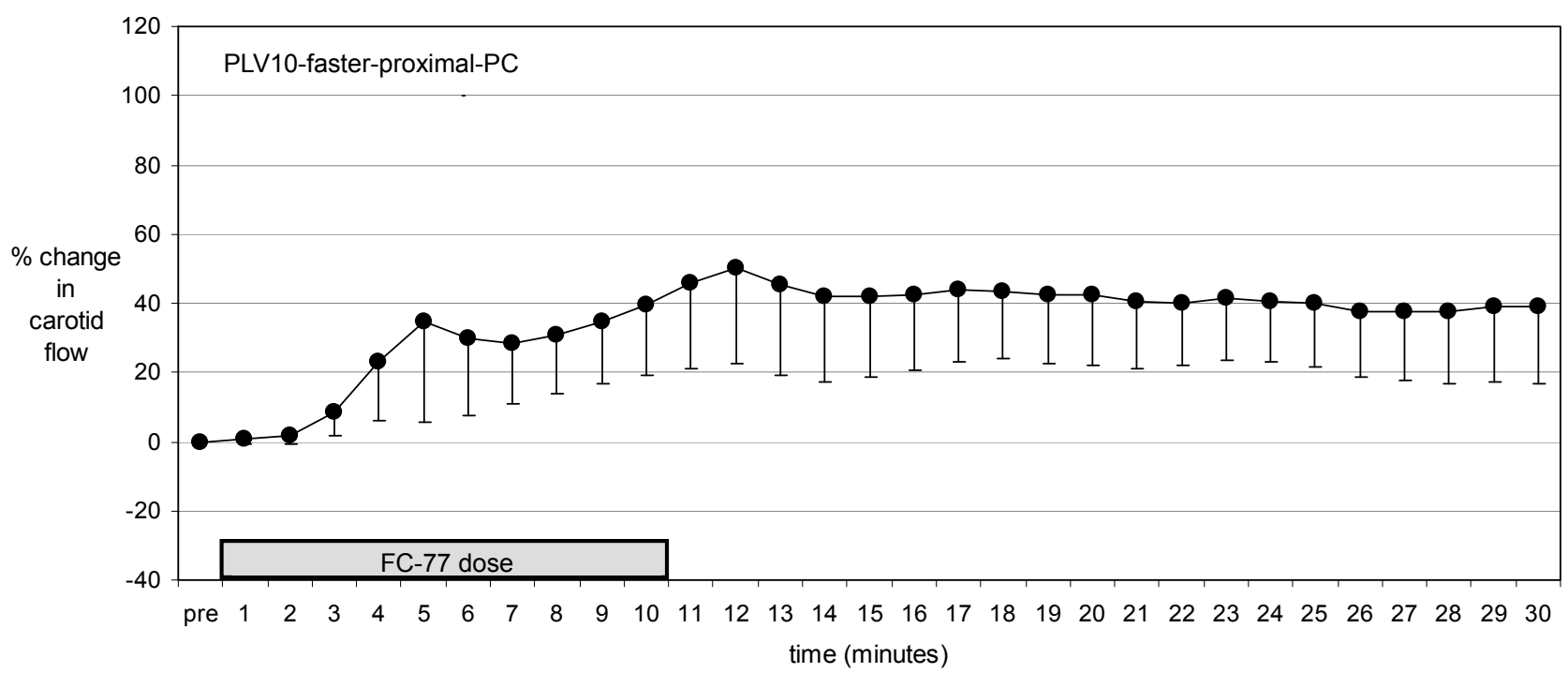

(d)

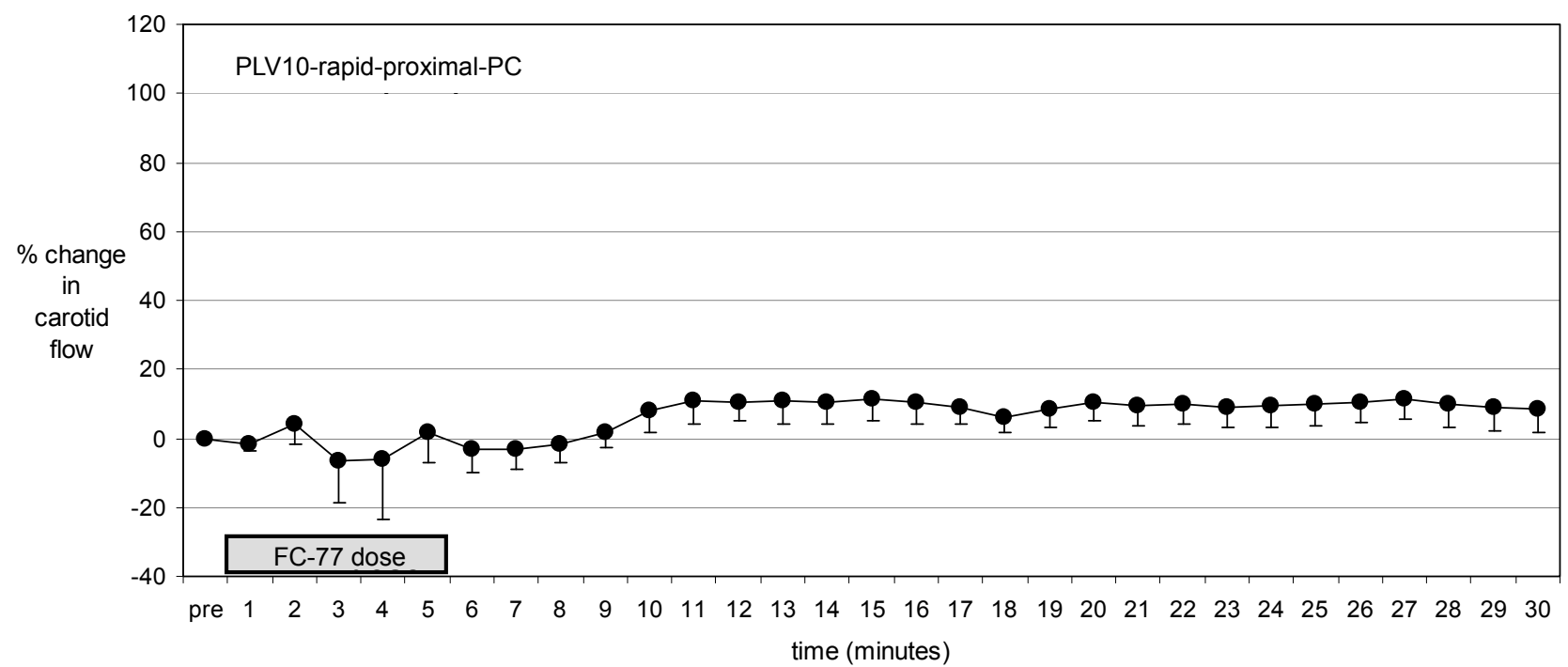

(e)

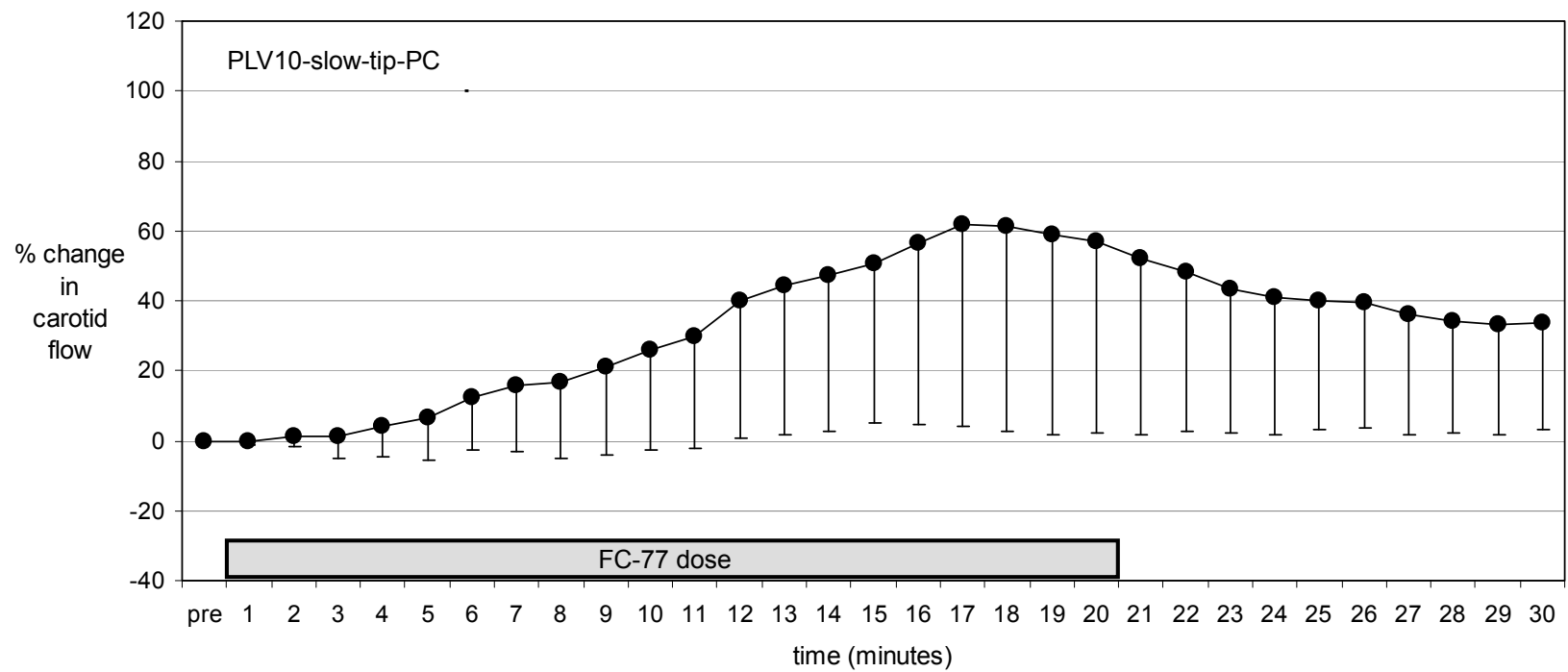

(f) 


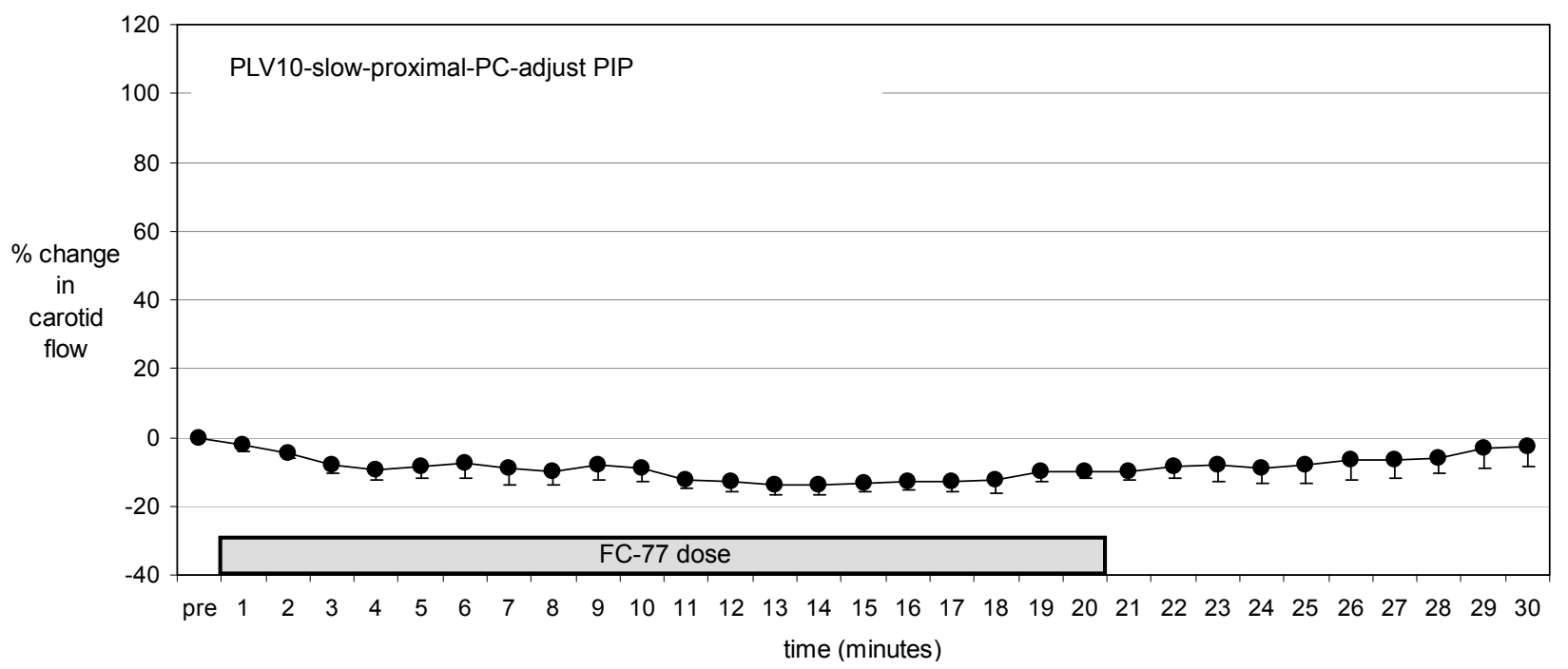

(g)

Figure 2. Relative changes (\% change from baseline) of carotid blood flow for each perfluorocarbon dosing strategy. All vertical scales are identical for ease of comparison.

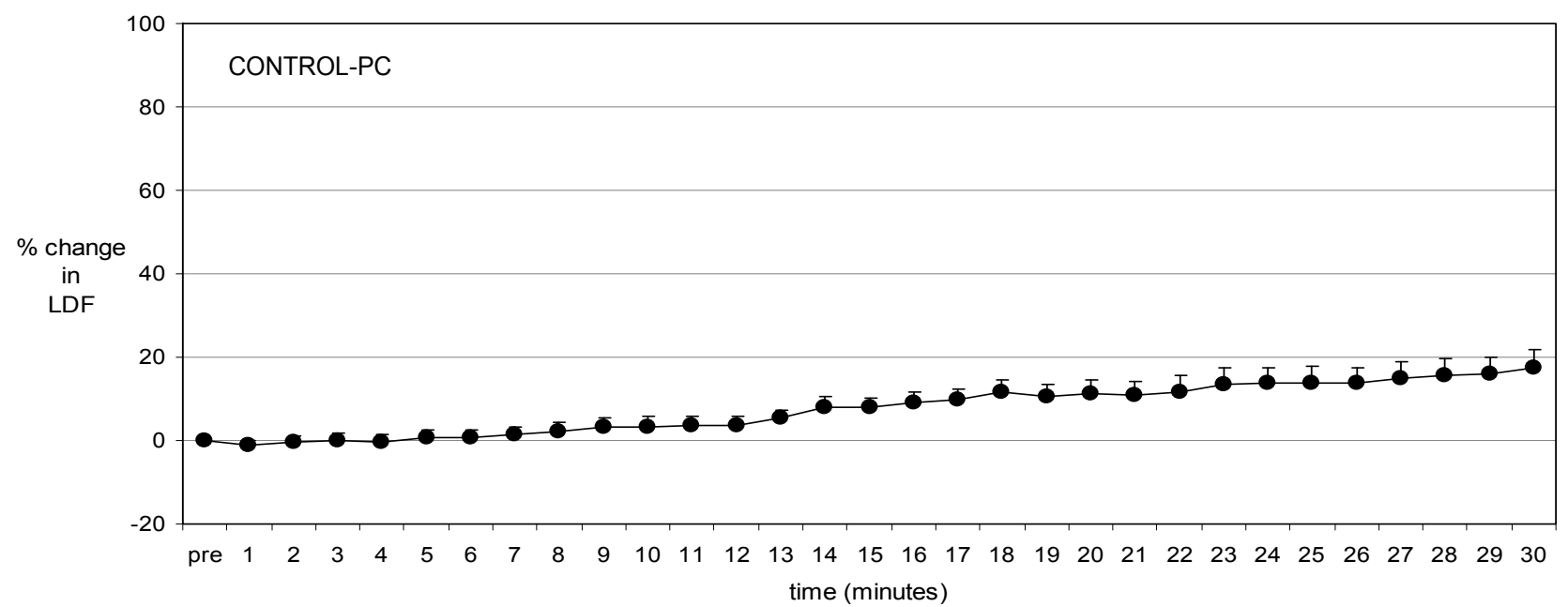

(a)

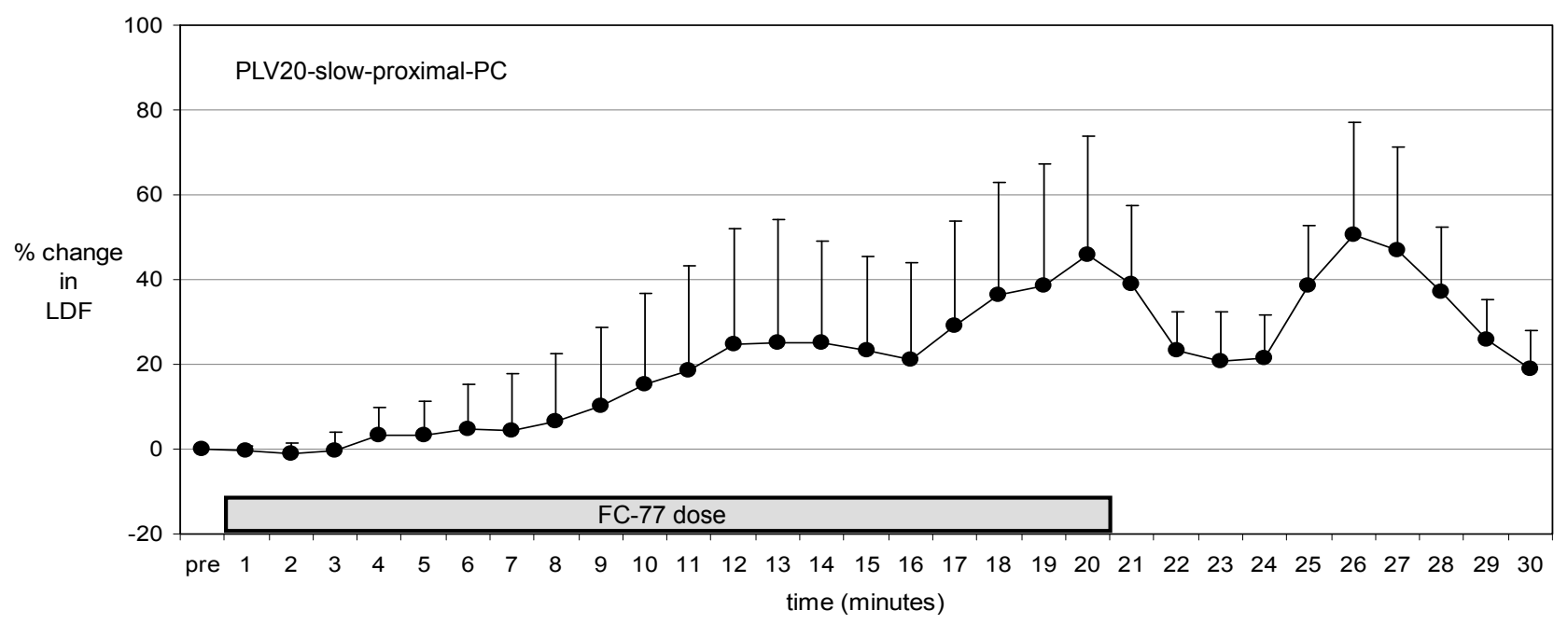

(b) 


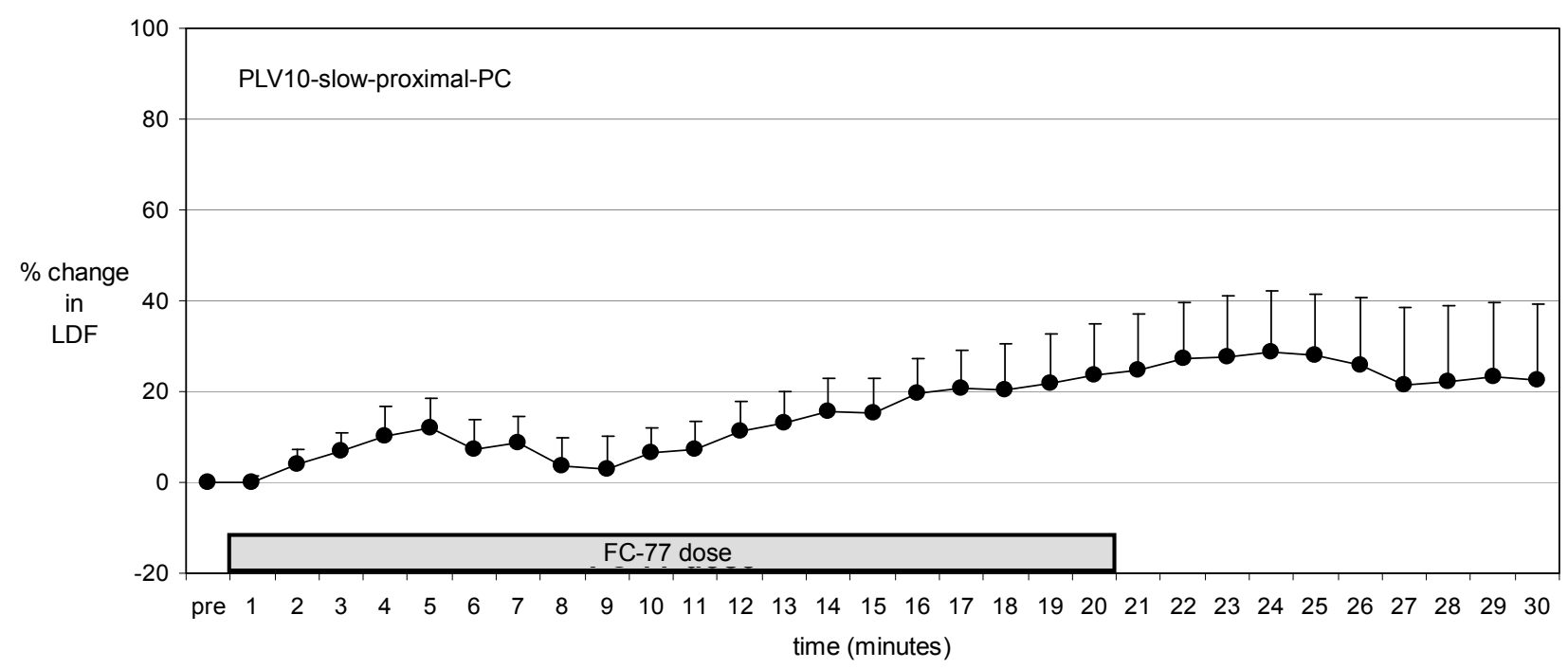

(c)

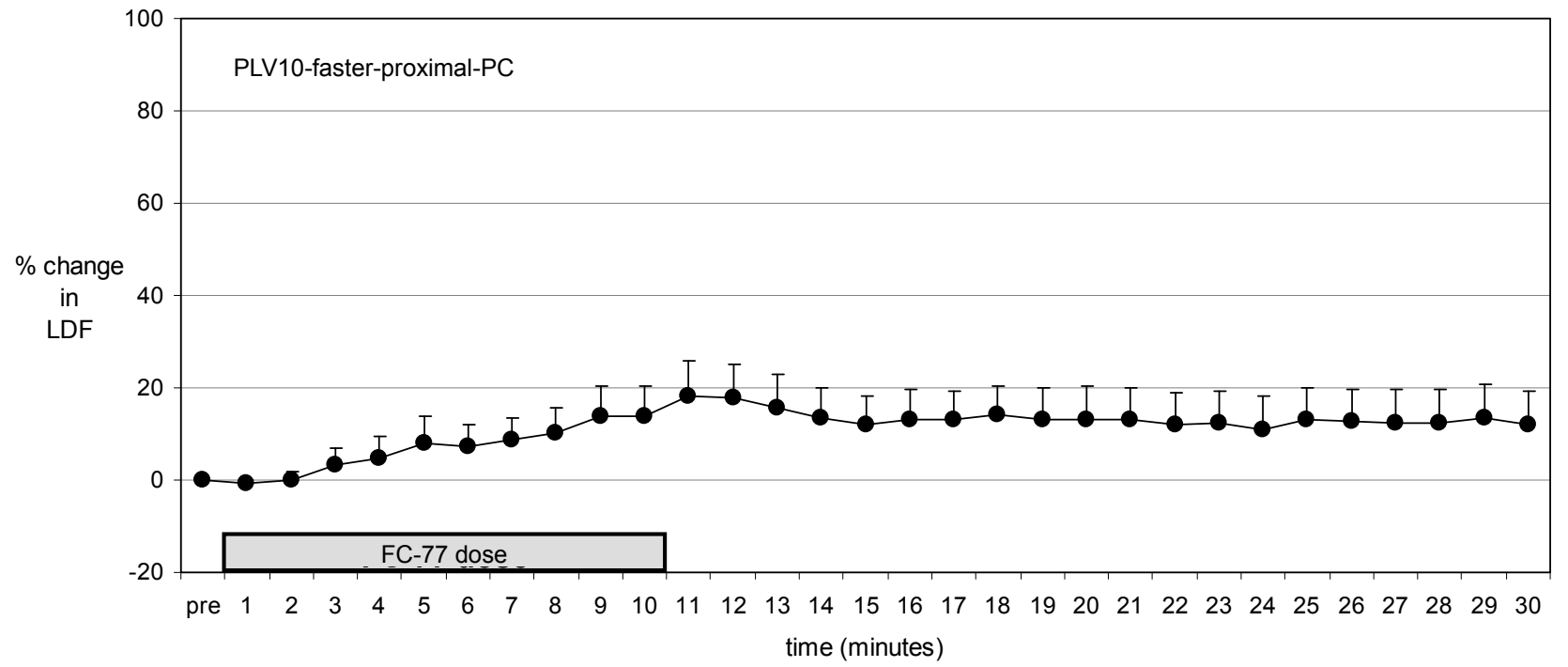

(d)

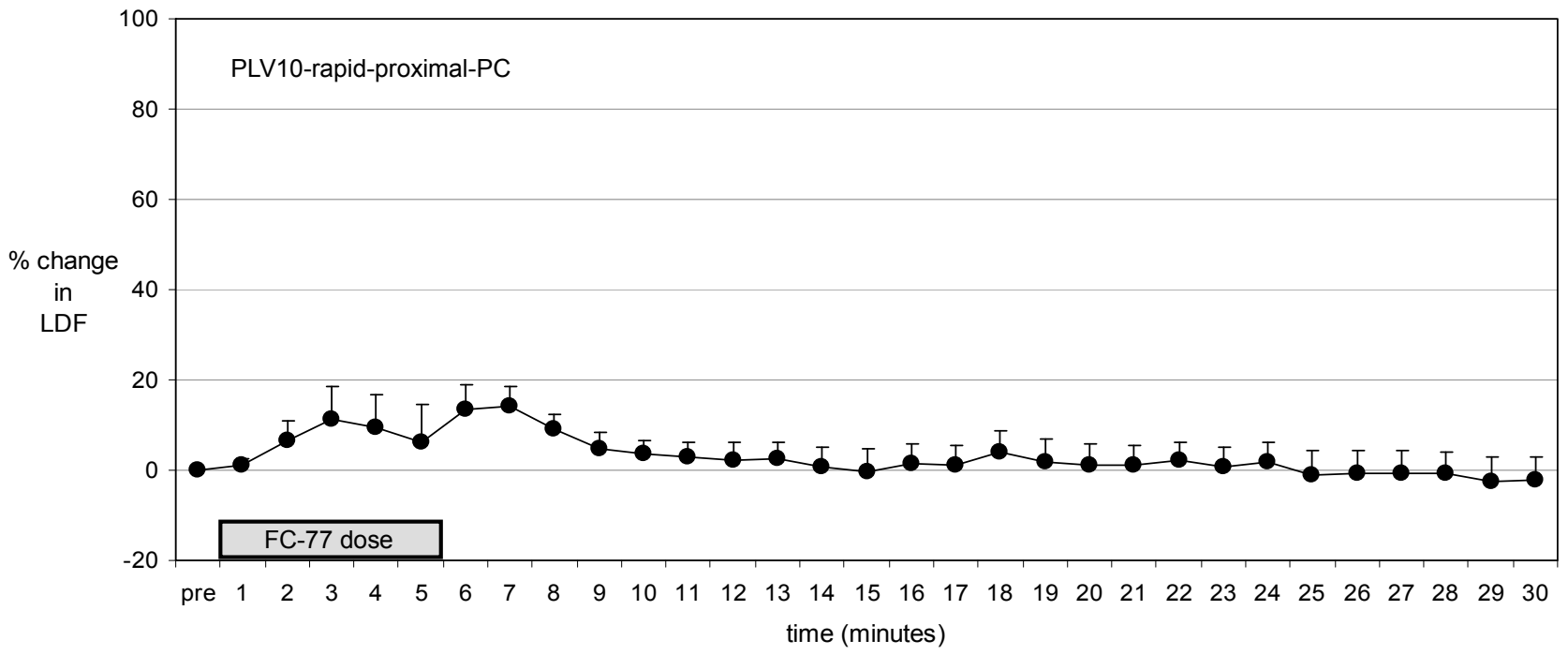

(e) 


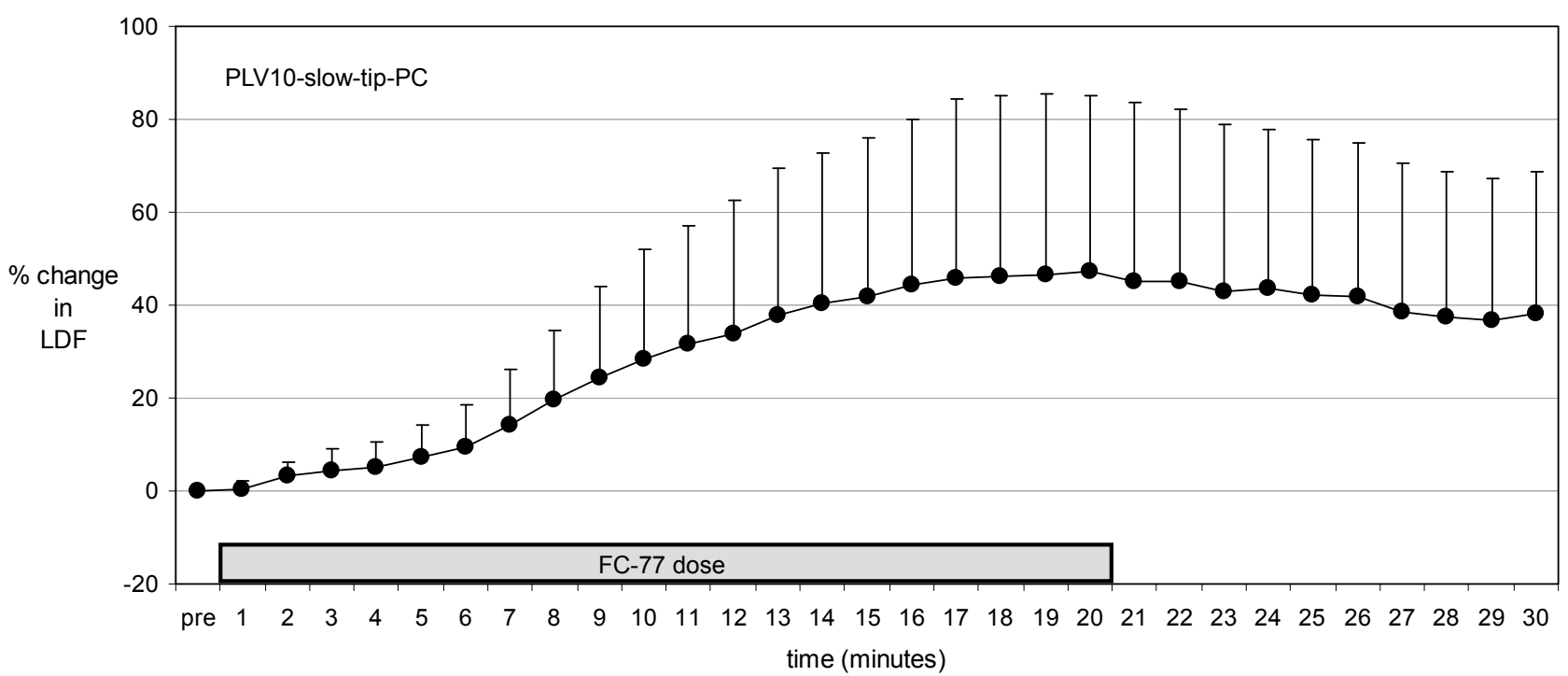

(f)

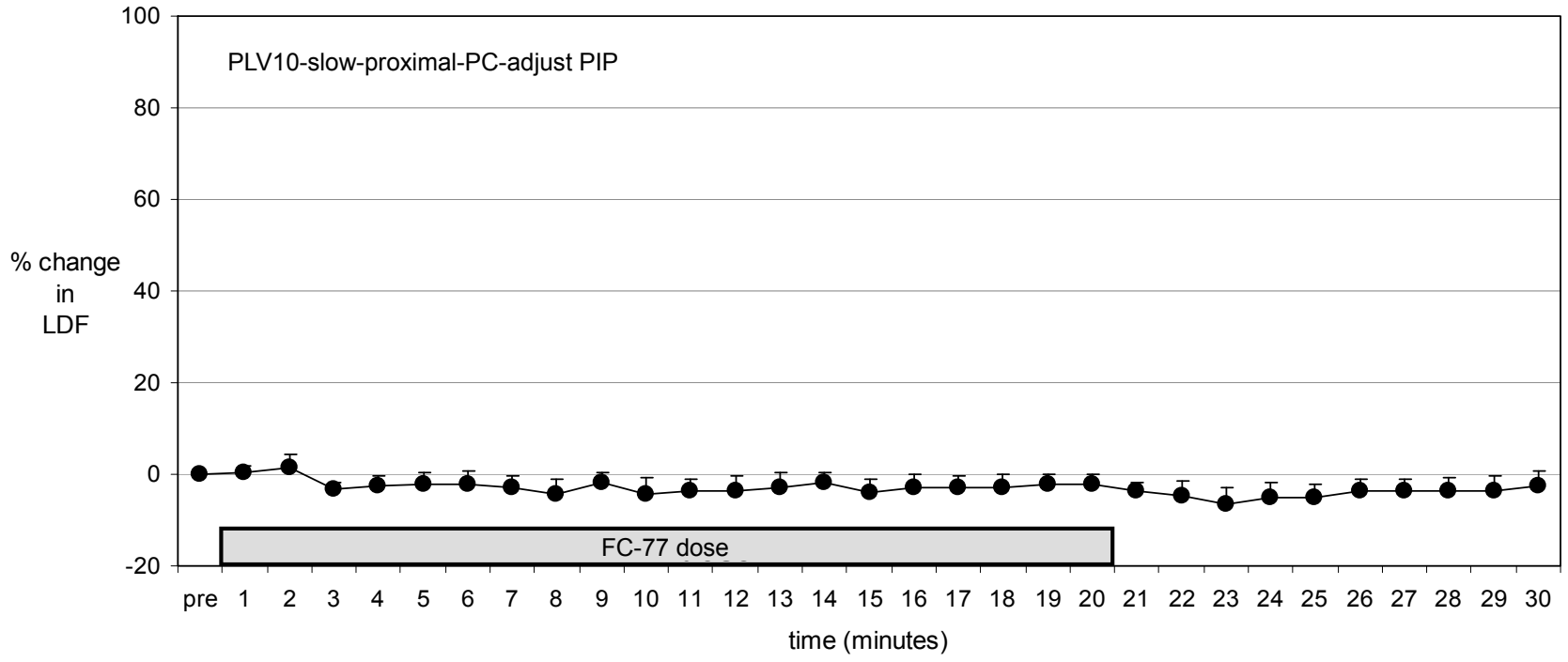

(g)

Figure 3. Relative changes (\% change from baseline) of cortical cerebral blood flow for each perfluorocarbon dosing strategy. All vertical scales are identical for ease of comparison.

Table 1. The extent of the relative changes of carotid blood flow.

\begin{tabular}{|c|c|c|c|c|}
\hline Group & PFC dose duration & $\begin{array}{c}\% \text { increase } \\
\text { at end of dose }\end{array}$ & $\begin{array}{c}\text { Maximum \% } \\
\text { increase (at time) }\end{array}$ & $\begin{array}{c}\text { Minimum \% } \\
\text { decrease (at time) }\end{array}$ \\
\hline CONTROL-PC & did not get PFC & did not get PFC & 4 (19 min) & $4(7 \mathrm{~min})$ \\
\hline PLV20-slow-proximal-PC & $20 \mathrm{~min}$ & 50 & $52(27 \mathrm{~min})$ & $3(2 \mathrm{~min})$ \\
\hline PLV10-slow-proximal-PC & $20 \mathrm{~min}$ & 95 & 105 (22 min) & no decrease \\
\hline PLV10-faster-proximal-PC & $10 \mathrm{~min}$ & 39 & $50(12 \mathrm{~min})$ & no decrease \\
\hline PLV10-rapid-proximal-PC & $5 \mathrm{~min}$ & 1 & 11 (11 min) & $6(3 \mathrm{~min})$ \\
\hline PLV10-slow-tip-PC & $20 \mathrm{~min}$ & 57 & $62(17 \mathrm{~min})$ & no decrease \\
\hline PLV10-slow-proximal-PC-adjust PIP & $20 \mathrm{~min}$ & -10 & no increase & 14 (14 min) \\
\hline
\end{tabular}

$\mathrm{PFC}$ - perfluorocarbon. 
Table 2. The extent of the relative changes of cortical cerebral blood flow.

\begin{tabular}{ccccc}
\hline Group & PFC dose duration & $\begin{array}{c}\text { \% increase } \\
\text { at end of dose }\end{array}$ & $\begin{array}{c}\text { Maximum \% } \\
\text { increase (at time) }\end{array}$ & $\begin{array}{c}\text { Minimum \% } \\
\text { decrease (at time) }\end{array}$ \\
\hline CONTROL-PC & did not get PFC & did not get PFC & $17(30 \mathrm{~min})$ & $1(1 \mathrm{~min})$ \\
PLV20-slow-proximal-PC & $20 \mathrm{~min}$ & 46 & $51(26 \mathrm{~min})$ & $1(2 \mathrm{~min})$ \\
PLV10-slow-proximal-PC & $20 \mathrm{~min}$ & 24 & $29(24 \mathrm{~min})$ & no decrease \\
PLV10-faster-proximal-PC & $10 \mathrm{~min}$ & 14 & $18(11 \mathrm{~min})$ & $1(1 \mathrm{~min})$ \\
PLV10-rapid-proximal-PC & $5 \mathrm{~min}$ & 6 & $14(7 \mathrm{~min})$ & $3(29 \mathrm{~min})$ \\
PLV10-slow-tip-PC & $20 \mathrm{~min}$ & 47 & $47(20 \mathrm{~min})$ & no decrease \\
PLV10-slow-proximal-PC-adjust PIP & $20 \mathrm{~min}$ & -2 & $2(2 \mathrm{~min})$ & $7(23 \mathrm{~min})$ \\
\hline
\end{tabular}

carotid blood flow was around 50\% in the PLV20-slowproximal-PC (Figures 2(a) and (b)). In the CONTROL-PC dosing event group the carotid blood flow remained with $\pm 5 \%$ of baseline throughout the $30 \mathrm{~min}$.

A similar increase in cortical cerebral blood flow was seen in the PLV20-slow-proximal-PC group (Figure 3(b)). In the CONTROL-PC dosing event group the laser Doppler flow increased slightly up to a maximum increase of around $18 \%$ whereas in the PLV20-slowproximal-PC group the laser Doppler flow increased to a maximum of about $50 \%$. The differences between groups was not statistically significant-Mann-Whitney test $p=0.31$ at the end of the dose and $p=0.24$ at the time of maximum difference (26 min).

During perfluorocarbon dosing there was more variability in carotid blood flow but this difference did not reach statistical significance-Mann-Whitney test $\mathrm{p}=$ 0.065 at the end of the dose and Student's t test Mann-Whitney test $p=0.18$ at the time of maximum difference $(30 \mathrm{~min})$. There was significantly more variability in cortical cerebral blood flow during perfluorocarbon dosing-Mann-Whitney test $\mathbf{p}=\mathbf{0 . 0 0 4 3}$ at the end of the dose and Mann-Whitney test $\mathbf{p}=\mathbf{0 . 0 4 1}$ at the time of maximum difference $(25 \mathrm{~min})$. See additional data file, pp. 3-5.

See additional data file (pp. 6-17) for the results of haemodynamics, vital signs and respiratory function.

\subsection{Does a Lower Dose of Perfluorocarbon Disturb Cerebral Blood Flow?}

We compared the PLV10-slow-proximal-PC group with the PLV20-slow-proximal-PC group.

Carotid blood flow increased over the 30 minute observation period in both groups (Figures 2(b) and (c)) but there was no difference between groups-Mann-Whitney test $p=0.82$ at the end of the dose and Mann-Whitney test $p=0.82$ at the time of maximum difference $(24 \mathrm{~min})$. The highest mean increase in carotid blood flow was around $105 \%$ in the PLV10-slow-proximal-PC group and around $50 \%$ in the PLV20-slow-proximal-PC group.

Whilst cortical cerebral blood flow increased in both groups (Figures 3(b) and (c)) there was no statistically significant difference between groups-Student's t test $p$ $=0.48$ at the end of the dose and Mann-Whitney test $\mathrm{p}=$ 0.59 at the time of maximum difference $(27 \mathrm{~min})$.

During perfluorocarbon dosing there was considerable variability in both carotid blood flow and cortical cerebral blood flow (see additional data file, pp. 18-20) but there were no statistically significant differences between groups. For the variability of carotid flow the MannWhitney test $p=0.065$ at the end of the dose and Student's t test $p=0.058$ at the time of maximum difference (3 min). For variability of cortical cerebral blood flow the Student's t test $p=0.48$ at the end of the dose and Mann-Whitney test $p=0.59$ at the time of maximum difference (27 min).

See additional data file (pp. 21-32) for the results of haemodynamics, vital signs and respiratory function.

\subsection{Do Different Rates of Administration Affect Cerebral Blood Flow?}

We compared the PLV10-slow-proximal-PC group, the PLV10-faster-proximal-PC group and the PLV10-rapidproximal-PC group.

Carotid blood flow increased during the initial dose of $10 \mathrm{~mL} / \mathrm{kg}$ perfluorocarbon when starting partial liquid ventilation in both the PLV10-slow-proximal-PC and PLV10-faster-proximal-PC groups (Figures 2(c) and (d)). In the PLV10-rapid-proximal-PC group the increase in carotid blood flow was much less pronounced (Figure 2(e)). The extent of the changes of carotid blood flow are shown in Table 1. The relative increase in carotid blood flow was greatest when the dose of perfluorocarbon was given slowly and least when the dose was given rapidly.

However, there were no statistically significant differences between groups for carotid blood flowKruskal-Wallis test $\mathrm{p}=0.26$ at the end of the dose and Kruskal-Wallis test $p=0.29$ at the time of maximum difference (23 $\mathrm{min})$.

Cortical cerebral blood flow increased in all three groups (Figures 3(c)-(e)). The pattern of changes were different between all three groups and the extent of the 
changes of cortical cerebral blood flow are shown in Table 2 . The relative increase in cortical cerebral blood flow was greatest when the dose of perfluorocarbon was given slowly (Figure 3(c)) and least when the dose was given rapidly (Figure 3(e)). Importantly when the dose was given rapidly (over 5 minutes) the cortical cerebral blood flow increased quickly but decreased back to around baseline by about 12 minutes. When the dose of perfluorocarbon is given over 10 or 20 minutes cortical cerebral blood flow remained increased throughout the 30 minute observation period. However, there were no statistically significant differences between groupsone-way ANOVA $p=0.40$ at the end of the dose and one-way ANOVA $p=0.12$ at the time of maximum difference (25 min).

During perfluorocarbon dosing there was a statistically significant difference between groups for variability in carotid blood flow-Kruskal-Wallis test $\mathrm{p}=0.16$ at the end of the dose and one-way ANOVA $p=0.02$ at the time of maximum difference $(18 \mathrm{~min})$. There was no statistically significant difference between groups for variability in cortical cerebral blood flow-KruskalWallis test $p=0.22$ at the end of the dose and KruskalWallis test $p=0.87$ at the time of maximum difference (1 min). See additional data file, pp. 33-35.

See additional data file (pp. 36-47) for the results of haemodynamics, vital signs and respiratory function.

\subsection{Does the Portal of Entry of the Dose of Perfluorocarbon Affect Cerebral Blood Flow?}

We compared the PLV10-slow-proximal-PC group with the PLV10-slow-tip-PC group. The PLV10-slow-proximal-PC group had a dose of FC-77 $(10 \mathrm{~mL} / \mathrm{kg})$ given over $20 \mathrm{~min}$ via the wye-piece at the proximal end of the ETT (Figure 1) whilst on pressure-controlled ventilation. The PLV10-slow-tip-PC group had $10 \mathrm{~mL} / \mathrm{kg}$ of FC-77 given over $20 \mathrm{~min}$ via the ETT tip lumen (Figure 1) whilst on pressure-controlled ventilation.

Carotid blood flow increased over the 30 minute observation period in both groups (Figures 2(c) and (f)). The differences were not statistically significant-MannWhitney test $p=0.39$ at the end of the dose and MannWhitney test $\mathrm{p}=0.48$ at the time of maximum difference (24 min). The highest mean increase in carotid blood flow was around $110 \%$ in the PLV10-slow-proximalPC group and around $60 \%$ in the PLV10-slow-tip-PC group.

Cortical cerebral blood flow increased in both groups (Figures 3(c) and (f)). The differences were not statisticcally significant-Mann-Whitney test $p=0.94$ at the end of the dose and Student's t test Mann-Whitney test $p=$ 0.94 at the time of maximum difference $(15 \mathrm{~min})$. The highest mean increase in cortical cerebral blood flow was around $47 \%$ in the PLV10-slow-tip-PC group and around 29\% in the PLV10-slow-proximal-PC group.

During perfluorocarbon dosing there were no statisticcally significant difference between the two groups for carotid blood flow variability-Mann-Whitney test $\mathrm{p}=$ 0.24 at the end of the dose and Mann-Whitney test $\mathrm{p}=$ 0.13 at the time of maximum difference $(3 \mathrm{~min})$. There was a little more variability in cortical cerebral blood flow in the PLV10-slow-proximal-PC group. The differences were not statistically significant-Mann-Whitney test $\mathrm{p}=0.80$ at the end of the dose and Mann-Whitney test $\mathrm{p}=0.093$ at the time of maximum difference $(2 \mathrm{~min})$. See additional data file (pp. 48-50).

See additional data file (pp. 51-62) for the results of haemodynamics, vital signs and respiratory function.

\subsection{Does Tight Control of Arterial Carbon Dioxide during Perfluorocarbon Mitigate the Effects on Cerebral Blood Flow?}

We compared the PLV10-slow-proximal-PC group with the PLV10-slow-proximal-PC-adjust PIP group.

The relative change in carotid blood flow (Figure 2(c)) showed a significant increase in the PLV10-slowproximal-PC group compared with the PLV10-slowproximal-PC-adjust PIP group which had a slight decrease (Figure 2(g)). These differences were statistically significant-Mann-Whitney test $p=0.015$ at the end of the dose and Mann-Whitney test $\mathrm{p}=0.015$ at the time of maximum difference $(24 \mathrm{~min})$. The highest increase in mean carotid blood flow was around $105 \%$ in the PLV10-slow-proximal-PC group and the lowest decrease was around $14 \%$ in the PLV10-slow-proximalPC-adjust PIP group.

Cortical cerebral blood flow showed a significant increase in the PLV10-slow-proximal-PC group (Figure 3(c)) compared with the PLV10-slow-proximal-PCadjust PIP group (Figure 3(g)) which had a slight decrease - Mann-Whitney test $p=0.041$ at the end of the dose and Mann-Whitney test $p=0.065$ at the time of maximum difference $(23 \mathrm{~min})$. The highest increase in mean cortical cerebral blood flow was around $29 \%$ in the PLV10-slow-proximal-PC group and the lowest decrease was around $7 \%$ in the PLV10-slow-proximalPC-adjust PIP group.

During perfluorocarbon dosing there was less variability in carotid blood flow in the PLV10-slow-proximalPC-adjust PIP group-Student's $t$ test $p=0.019$ at the end of the dose and Mann-Whitney test $p=0.065$ at the time of maximum difference ( $5 \mathrm{~min}$ ). There was no difference between groups for the variability of cortical cerebral blood flow-Student's $t$ test $p=0.94$ at the end of the dose and Mann-Whitney test $p=0.39$ at the time of maximum difference $(2 \mathrm{~min})$. See additional data file (pp. 63-65). 
See additional data file (pp. 66-77) for the results of haemodynamics, vital signs and respiratory function.

\section{DISCUSSION}

\subsection{Summary of Findings from the Current Study}

Right carotid blood flow was increased during tracheal perfluorocarbon dosing with $20 \mathrm{~mL} / \mathrm{kg}$ of FC-77 at the start of partial liquid ventilation in rabbits. Similar, non-statistically significant effects were seen in cortical cerebral blood flow. The variability in cortical cerebral blood flow was increased. Similar, almost statistically significant effects were seen in carotid blood flow variability. There was also a decrease in $\mathrm{pH}$ (mirrored by changes in $\mathrm{PaCO}_{2}$ ).

Cortical cerebral blood flow and right carotid blood flow were not different when using $10 \mathrm{~mL} / \mathrm{kg}$ of perfluorocarbon compared with $20 \mathrm{~mL} / \mathrm{kg}$. There were no significant differences in variability of cortical cerebral blood flow and right carotid blood flow.

Cerebral blood flow did not differ with the rate of administration of $10 \mathrm{~mL} / \mathrm{kg}$ of perfluorocarbon when starting partial liquid ventilation. The variability in carotid blood flow was increased when the dose is given rapidly. The effect on cerebral blood flow variability would seem to be of most clinical importance in the first minutes of rapid dosing.

Changes in cerebral blood flow are similar regardless of the portal of entry of the perfluorocarbon dose, i.e., at the wye-piece at the proximal end of the endotracheal tube or the tip of the endotracheal tube.

If the peak inspiratory pressure was adjusted during perfluorocarbon dosing, to maintain the arterial carbon dioxide between 45 and $50 \mathrm{mmHg}$, then there was no increase in cerebral blood flow and there was less variability in carotid blood flow.

\subsection{Interpretation of the Results}

Despite the lack of statistically significant betweengroup differences in $\mathrm{PaCO}_{2}$ there was a consistent association between increased $\mathrm{PaCO}_{2}$ and increased cerebral blood flow. In five of the dosing strategies used the $\mathrm{PaCO}_{2}$ increased during perfluorocarbon dosing, and in four of those five the tidal volumes decreased. The effect on tidal volumes, and hence minute ventilation, is not unexpected in animal models where there is no lung disease, particularly when no adjustment is made in peak inspiratory pressures. Partial liquid ventilation is known to decrease lung compliance in normal lungs, and it also partially blocks endotracheal tubes during perfluorocarbon instillation, increasing the airway resistance [19-21]. Both lead to decreased tidal volumes and/or increased tidal volumes to maintain $\mathrm{PaCO}_{2}$ [22]. Also $\mathrm{PaO}_{2}$ is known to be lower during partial liquid ventilation in animals with normal lungs $[15,23]$. The most compelling data that it is simply a decrease in tidal volume that caused the rise in $\mathrm{PaCO}_{2}$ is that during the dosing strategy where the $\mathrm{PaCO}_{2}$ was closely targeting by adjusting peak inspiratory pressure the tidal volumes were not decreased.

We have no evidence from the current study to suggest that any other factors were operating during the perfluorocarbon dosing episodes in rabbits to increase cerebral blood flow. Using adult animals excludes a change in shunt across a patent ductus arteriosus as a cause for the increase in cerebral blood flow. Similarly none of the rabbits had any hypoxic-ischaemic events making any post-hypoxic-ischaemic hyperperfusion very unlikely during any of the dosing episodes. None of the rabbits were hyperthermic at any stage during any of the dosing episodes; also during those dosing strategies where there was an increase in cerebral blood flow there was no corresponding increase in temperature.

There have been other published reports of studies investigating the effect of partial liquid ventilation on cerebral blood flow $[8,9,22,24-26]$. Two of the reports are our previous studies in preterm lambs [8,9]. Only one of the other studies reported measurements during perfluorocarbon dosing but in this study there was no control group for comparison [24]. The studies are discussed below.

\subsection{Comparison with Other Studies}

Burkhardt et al. [24] report the only other study that has investigated the effects of perfluorocarbon dosing on cerebral concentration of total and oxygenated haemoglobin using near infrared spectroscopy. They used newborn piglets of around $730 \mathrm{~g}$ and $<24$ hours old without lung disease. They were randomised to one of three different dosing regimens of PF5080:

- $10 \mathrm{~mL} / \mathrm{kg}$ given over about six minutes, target filling rate of $1.5 \mathrm{~mL} / \mathrm{min}[\sim 2.1 \mathrm{~mL} / \mathrm{kg} / \mathrm{min}]$; or

- $30 \mathrm{~mL} / \mathrm{kg}$ given over about 16 minutes, target filling rate of $1.5 \mathrm{~mL} / \mathrm{min}[\sim 2.1 \mathrm{~mL} / \mathrm{kg} / \mathrm{min}]$; or

- $30 \mathrm{~mL} / \mathrm{kg}$ given over about 41 seconds, target filling over 30 - $45 \mathrm{~s}$ [ 40 - $60 \mathrm{~mL} / \mathrm{kg} / \mathrm{min}]$.

The cerebral concentration of oxygenated haemoglobin decreased initially (at 1 minute) when $30 \mathrm{~mL} / \mathrm{kg}$ was given rapidly, with return to baseline by $3 \mathrm{~min}$. There was no decrease with $30 \mathrm{~mL} / \mathrm{kg}$ given slowly nor when $10 \mathrm{~mL} / \mathrm{kg}$ was administered. At $5 \mathrm{~min}$ and thereafter the cerebral concentration of oxygenated haemoglobin increased in both $30 \mathrm{~mL} / \mathrm{kg}$ groups but not in the $10 \mathrm{~mL} / \mathrm{kg}$ group. In both $30 \mathrm{~mL} / \mathrm{kg}$ groups the total cerebral haemoglobin concentration increased compared with the 10 $\mathrm{mL} / \mathrm{kg}$ group. Similarly in both $30 \mathrm{~mL} / \mathrm{kg}$ groups the $\mathrm{PaCO}_{2}$ increased and $\mathrm{PaO}_{2}$ decreased but not in the 10 
$\mathrm{mL} / \mathrm{kg}$ group.

There was no control group, therefore conclusions cannot be drawn about the effect of perfluorocarbon dosing compared with gas ventilation alone. The study design makes direct comparisons between the two volumes of perfluorocarbon given difficult because the doses were also given over different durations. Interpretation is also difficult as they did not measure cerebral blood flow directly, did not record and report real-time haemodynamic variables during the perfluorocarbon liquid dosing, and only reported changes in cerebral oxygenation at discrete time points.

Burkhardt et al. [24] concluded that giving perfluorocarbon extremely rapidly (20 - 30 times faster than the rabbits in our "rapid" group) is not recommended because of the decrease in cerebral blood flow (as determined by total cerebral haemoglobin concentration) during perfluorocarbon dosing.

The three different rates of administration in our rabbit studies were:

- slow- $10 \mathrm{~mL} / \mathrm{kg}$ over $20 \mathrm{~min}-0.5 \mathrm{~mL} / \mathrm{kg} / \mathrm{min}$;

- faster- $10 \mathrm{~mL} / \mathrm{kg}$ over $10 \mathrm{~min}-1.0 \mathrm{~mL} / \mathrm{kg} / \mathrm{min}$;

- rapid- $10 \mathrm{~mL} / \mathrm{kg}$ over $5 \mathrm{~min}-2.0 \mathrm{~mL} / \mathrm{kg} / \mathrm{min}$.

The volume and rate of administration in our "rapid" group in rabbits were almost identical to the volume and rate in the Burkhardt [24] $10 \mathrm{~mL} / \mathrm{kg}$ group and similar results were seen: they found no changes in $\mathrm{PaCO}_{2}$ or total cerebral haemoglobin concentration. We found a slight increase (maximum 14\%) in cerebral blood flow during dosing with a much lower increase in cerebral blood flow compared with the slower administration rates.

Our previous studies $[8,9]$ investigated the effect of perfluorocarbon dosing in preterm lambs. We showed that an intratracheal loading dose of $30 \mathrm{~mL} / \mathrm{kg}$ of perfluorocarbon liquid, instilled over $20 \mathrm{~min}$, caused an increase in cortical cerebral blood flow (measured continuously with laser Doppler) during the administration of perfluorocarbon and immediately thereafter. The highest mean increase in the partial liquid ventilation group was $27 \%$. There was a slightly lower mean arterial blood pressure in the partial liquid ventilation group; the heart rate did not differ between groups. The $\mathrm{PaCO}_{2}$ was marginally higher in the partial liquid ventilation group at $30 \mathrm{~min}$ - the difference between groups was not statistically significant. These lambs who received $30 \mathrm{~mL} / \mathrm{kg}$ were compared with lambs that received either 20 or 40 $\mathrm{mL} / \mathrm{kg}$. Cortical cerebral blood flow increased over time in all three groups but there was no difference between groups. There was no statistically significant difference in $\mathrm{PaCO}_{2}$ between groups, but this was only measured at baseline and at 30 minutes.

Therefore, in preterm lambs there was a consistent effect of perfluorocarbon dosing causing increased cerebral blood flow. There did not seem to be any haemodynamic cause for the increased cerebral blood flow but we could not rule out an increase in $\mathrm{PaCO}_{2}$. Our rabbit studies have demonstrated similar increases in cerebral blood flow with perfluorocarbon dosing and associated increases in $\mathrm{PaCO}_{2}$. It is also possible that in a lamb with a left-to-right shunt across a patent ductus arteriosus (i.e., with decreased cerebral blood flow) that an increase in pulmonary vascular resistance could decrease the leftto-right shunt and cause a relative increase in cerebral blood flow. Our rabbit model has ruled out an effect from a patent ductus arteriosus.

\subsection{Choice of Rabbit Model}

In order to study the effects of many different dosing strategies a simple and reliable model of the effects of perfluorocarbon administration on cerebral blood flow was needed. The use of adult New Zealand white rabbits provides an animal model with the following advantages. They are in the neonatal size-range (similar to the preterm lambs previously studied). The procedures involved are readily performed in rabbits of this size and they are familiar to the investigators. Using rabbits of this size, with no lung disease, gives a far more stable animal that allows repeated study over many hours, as they are robust enough to tolerate multiple dosing procedures. There is no requirement to do experiments on particular days as with date-mated ewes and their lambs. The confounding factors of lung disease and/or patent ductus arteriosus are eliminated. There is no perinatal asphyxia. Adult New Zealand white rabbits allowed the use of an animal in which we could measure continuous cerebral blood flow-laser Doppler as a reliable measure of cerebral blood flow has been validated in adult New Zealand white rabbits. They also allowed the use two different methods of measuring continuous cerebral blood flowcarotid flow and cortical cerebral blood flow.

The different dosing strategies were studied in multiple sequences in single animals: others have also used this approach. Individual rabbits were not allocated dosing strategies: each dosing event was randomly allocated a different dosing strategy. This allowed an absolute minimum number of animals to be used. The PLV10slow-proximal-PC group served as the reference strategy for perfluorocarbon dosing. All the dosing strategies experimental runs were done contemporaneously using identical methods in the same laboratory with the same personnel. As best we could be assured at the time only the dosing strategy differed significantly for any given run. Differences between dosing strategy groups at baseline were controlled for with the statistical analysis used with the data converted to "change from baseline". All dosing strategies were randomly allocated and allocation was concealed until just before each episode of per- 
fluorocarbon dosing. A post hoc analysis of the distribution of individual rabbits within each dosing strategy group showed no statistically significant difference compared with that expected by chance for the 11 rabbits (Chi squared test, $p=0.98$ ). Similarly the distribution of the order of the dosing events for each rabbit within each dosing strategy group showed no statistically significant difference compared with that expected by chance (Chi squared test, $\mathrm{p}=0.32$ ). Furthermore the oxygen indices were remarkably similar between all comparison dosing event groups with low average oxygen indices ranging from 1.5 to 2.0 . This is consistent with minimal lung disease across all dosing strategy groups for all comparisons.

\subsection{Implications}

From the results of the current study no direct conclusions about the effects in preterms can be made. However, given that the effect of perfluorocarbon dosing is the same in rabbits as that which we found in preterm lambs $[8,9]$ it is likely that the effects seen with different dosing strategies will also been in preterm lambs.

Our studies were born out of a desire to ensure that if partial liquid ventilation was to be used in extremely preterm infants that we should first know whether the instillation of perfluorocarbon disturbs cerebral blood flow which would put the infants at risk of brain injury. If cerebral blood flow is disturbed then it is necessary to determine if the dose of perfluorocarbon can be given safely without any cerebral blood flow disturbance. Given the potential for harm associated with perfluorocarbon dosing in the most vulnerable of preterm infants it is reassuring to know that there are ways of giving perfluorocarbon that can mitigate any increase in cerebral blood flow. This can be achieved best by either monitoring $\mathrm{PaCO}_{2}$ continuously during perfluorocarbon dosing and keeping it under tight control; not giving the dose over 5 minutes or faster; and not using the secondary lumen of an endotracheal tube.

If partial liquid ventilation is to be used, then the best protection for the extremely preterm brain is to start it safely without disturbing cerebral blood flow. Data from these studies will enable optimisation of the dosing method to be used. Given the availability of a suitable product, randomised controlled trials of partial liquid ventilation in neonates are both feasible and desirable $[27,28]$. Now the design of such trials can incorporate the findings of this study to make the dosing procedure as safe as it can be for use in extremely preterm infants.

\section{CONCLUSIONS}

The following effects were seen during perfluorocarbon dosing at the start of partial liquid ventilation in rabbits:
- Compared with conventional gas ventilation right carotid blood flow increased during perfluorocarbon dosing with $20 \mathrm{~mL} / \mathrm{kg}$. Similar, non-statistically significant effects were seen in cortical cerebral blood flow. There was also increased variability in cortical cerebral blood flow and similar, almost statistically significant, effects were seen in carotid blood flow variability. The effects on cerebral blood flow were similar to that seen in preterm lambs with lung disease.

- Cortical cerebral blood flow and right carotid blood flow were not different when using $10 \mathrm{~mL} / \mathrm{kg}$ of perfluorocarbon compared with $20 \mathrm{~mL} / \mathrm{kg}$. There were no significant differences in variability of cortical cerebral blood flow and right carotid blood flow. The lack of any significant differences between dose volume groups on cortical cerebral blood flow was similar to that seen in preterm lambs.

- Cerebral blood flow did not differ with the rate of administration of $10 \mathrm{~mL} / \mathrm{kg}$ of perfluorocarbon when starting partial liquid ventilation. The variability in carotid blood flow was increased, but this did not seem to be a consistent or clinically important difference.

- The increase in cortical cerebral blood flow and right carotid flow (and their variability) were similar when the dose was given at the endotracheal tube tip (via a secondary lumen in the wall of the endotracheal tube) compared with doses given more proximally.

- If the peak inspiratory pressure was adjusted during perfluorocarbon dosing to maintain the arterial carbon dioxide between 45 and $50 \mathrm{mmHg}$ then there was no increase in cerebral blood flow and there was less variability in carotid blood flow.

\section{ACKNOWLEDGEMENTS}

We gratefully acknowledge financial support from The Prince Charles Hospital Foundation, the Royal Women's Hospital Paul Weedon Bursary, and the Royal Women's Hospital Auxiliary.

Many thanks to Kathy Wilson who contributed significantly to the work in the animal laboratory. Thanks also to Michael Lindeberg and Bill Sommers who helped out in the animal laboratory. Thanks to Peter O’Rourke for his statistical advice.

\section{REFERENCES}

[1] Costeloe, K., Hennessy, E., Gibson, A.T., Marlow, N. and Wilkinson, A.R. (2000) The EPICure study: Outcomes to discharge from hospital for infants born at the threshold of viability. Pediatrics, 106, 659-671. doi:10.1542/peds.106.4.659

[2] Hennessy, E.M., Bracewell, M.A., Wood, N., Wolke, D., Costeloe, K., Gibson, A. and Marlow, N. for the EPICure 
Study Group (2008) Respiratory health in pre-school and school age children following extremely preterm birth. Archives of Diseases in Childhood, 93, 1037-1043. doi:10.1136/adc.2008.140830

[3] Leach, C.L., Greenspan, J.S., Rubenstein, S.D., Shaffer, T.H., Wolfson, M.R., Jackson, J.C., DeLemos, R. and Fuhrman, B.P. for the LiquiVent Study Group (1996) Partial liquid ventilation with perflubron in premature infants with severe respiratory distress syndrome. The New England Journal of Medicine, 335, 761-767. doi:10.1056/NEJM199609123351101

[4] Blassnig, N., Dietl, S., Tschirch, E., Burkhardt, W., Wemhöner, A. and Rüdiger, M. (2009) Intratracheal application of PFC diminishes the hyperoxia-mediated impairment of postnatal lung development. Acta Paediatrica, 98, 7.

[5] Vohr, B. and Ment, L.R. (1996) Intraventricular hemorrhage in the preterm infant. Early Human Development, 44, 1-16. doi:10.1016/0378-3782(95)01692-9

[6] Ballabh, P. (2010) Intraventricular hemorrhage in premature infants: mechanism of disease. Pediatric Research, 67, 1-8. doi:10.1203/PDR.0b013e3181c1b176

[7] Perlman, J.M. (2009) The relationship between systemic hemodynamic perturbations and periventricular-intraventricular hemorrhage-A historical perspective. Seminars in Pediatric Neurology, 16, 191-199. doi:10.1016/j.spen.2009.09.006

[8] Davies, M.W., Dunster, K.R., Wilson, K. and Colditz, P.B. (2010) Perfluorocarbon dosing when starting partial liquid ventilation: Haemodynamics and cerebral blood flow in preterm lambs. Neonatology, 97, 144-153. doi: $10.1159 / 000239768$

[9] Davies, M.W., Dunster, K.R., Wilson, K. and Colditz, P.B. (2010) The effect of the dose volume of perfluorocarbon when starting partial liquid ventilation. Journal of Paediatrics and Child Health, 46, 714-722. doi:10.1111/j.1440-1754.2010.01828.x

[10] Dunster, K.R. and Davies, M.W. (2004) A novel mounting device to attach intracranial probes to the skull for use in experimental research models. Physiological Measurement, 25, N11-N14. doi:10.1088/0967-3334/25/2/N01

[11] Tutuncu, A.S., Faithfull, N.S. and Lachmann, B. (1993) Comparison of ventilatory support with intratracheal perfluorocarbon administration and conventional mechanical ventilation in animals with acute respiratory failure. American Journal of Respiratory and Critical Care Medicine, 148, 785-792. doi:10.1164/ajrccm/148.3.785

[12] Lim, C.M., Domino, K.B., Glenny, R.W. and Hlastala, M.P. (2001) Effect of increasing perfluorocarbon dose on VA/Q distribution during partial liquid ventilation in acute lung injury. Anesthesiology, 94, 637-642. doi:10.1097/00000542-200104000-00018

[13] Lim, C.-M., Yang, S.-H., Kang, J.-L. and Koh, Y. (2002) Effect of ventilation mode on gas exchange during partial liquid ventilation at different perfluorocarbon doses in surfactant-depleted lung. Lung, 179, 245-255. doi:10.1007/s004080000065

[14] Suh, G.Y., Chung, M.P., Park, S.J., Koh, Y., Kang, K.W., Kim, H., Han, J., Rhee, C.H. and Kwon, O.J. (2000) Par- tial liquid ventilation shows dose-dependent increase in oxygenation with PEEP and decreases lung injury associated with mechanical ventilation. Journal of Critical Care, 15, 103-112. doi:10.1053/jcrc.2000.16463

[15] Fessler, H.E. and Pearse, D. (2000) Accuracy of hemodynamic measurements during partial liquid ventilation with perflubron. American Journal of Respiratory and Critical Care Medicine, 162, 1372-1376.

[16] Davies, M.W. and Dunster, K.R. (2000) The effect of perfluorocarbon vapour on the measurement of respiretory tidal volume during partial liquid ventilation. Physiological Measurement, 21, N23-N30. doi:10.1088/0967-3334/21/3/402

[17] Takeuchi, T., Horiuchi, J. and Terada, N. (1989) Central vasomotor control of the rabbit portal vein. Pflügers Archiv European Journal of Physiology, 413, 348-353. doi:10.1007/BF00584482

[18] National Health and Medical Research Council (Australia) (2004) Australian code of practice for the care and use of animals for scientific purposes. 7th Edition, Australian Government Publishing Service, Canberra.

[19] Weiswasser, J., Lueders, M. and Stolar, C.J.H. (1998) Pressure- versus volume-cycled ventilation in liquid-ventilated neonatal piglet lungs. Journal of Pediatric Surgery, 33, 1158-1162. doi:10.1016/S0022-3468(98)90551-6

[20] Hummler, H.D., Schulze, A., Pohlandt, F. and Thome, U. (2000) Dynamics of breathing during partial liquid ventilation in spontaneously breathing rabbits supported by elastic and resistive unloading. Pediatric Research, 47, 392-397. doi:10.1203/00006450-200003000-00018

[21] Shashikant, M.P., Badellino, M.M., Cooper, B., Shaffer, T.H., Myers, S.I. and Wolfson, M.R. (2002) Physicochemical properties of perfluorochemical liquids influence ventilatory requirements, pulmonary mechanics, and microvascular permeability during partial liquid ventilation following intestinal ischemia/reperfusion injury. Critical Care Medicine, 30, 2300-2305. doi:10.1097/00003246-200210000-00019

[22] Burkhardt, W., Proquitté, H., Krause, S., Wauer, R.R. and Rüdiger, M. (2004) Changes in $\mathrm{FiO}_{2}$ affect $\mathrm{PaO}_{2}$ with minor alterations in cerebral concentration of oxygenated hemoglobin during liquid ventilation in healthy piglets. Intensive Care Medicine, 30, 315-320. doi:10.1007/s00134-003-2090-7

[23] Hernan, L.J., Fuhrman, B.P., Papo, M.C., Steinhorn, D.M., Leach, C.L., Salman, N., Paczan, P.R. and Kahn, B. Cardiorespiratory effects of perfluorocarbon-associated gas exchange at reduced oxygen concentrations. Critical Care Medicine, 23, 553-559. doi:10.1097/00003246-199503000-00022

[24] Burkhardt, W., Proquitté, H., Krause, S., Wauer, R.R. and Rüdiger, M. (2002) Cerebral oxygenation is affected by filling mode and perfluorochemical volume in partial liquid ventilation of healthy piglets. Biology of the Neonate, 82, 250-256. doi:10.1159/000065886

[25] McLaughlin, G.E., Kulatunga, S., Kuluz, J.W., Gelman, B. and Schleien, C.L. (2001) Cerebral blood flow during partial liquid ventilation in surfactant deficient lungs under varying ventilation strategies. Pediatric Critical Care 
Medicine, 2, 88-92.

doi:10.1097/00130478-200101000-00017

[26] Dimmitt, R.A., Beckman, S.A., Halamek, L.P., Moss, R.L., Mickas, N.A., Falco, D.A., Chubb, C. and Skarsgard, E.D. (2002) Effects of partial liquid ventilation on cerebral blood flow and cerebral metabolism in neonatal lambs. Journal of Pediatric Surgery, 37, 840-844. doi:10.1053/jpsu.2002.32884
[27] Wolfson, M.R. and Shaffer, T.H. (2005) Pulmonary applications of perfluorochemical liquids: Ventilation and beyond. Paediatric Respiratory Reviews, 6, 117-127. doi:10.1016/j.prrv.2005.03.010

[28] Greenough, A. (2006) High frequency oscillation and liquid ventilation. Paediatric Respiratory Reviews, 7, S186S188. doi:10.1016/j.prrv.2006.04.207

\begin{abstract}
Abbreviations
ANOVA: Analysis of variance;

Cdyn: Dynamic compliance;

CI: Confidence interval;

CV: Coefficient of variation;

ETT: Endotracheal tube;

$\mathrm{FiO}_{2}$ : Fraction of inspired oxygen;

LDF: Laser Doppler flow;
\end{abstract}

MuLETT: Multi-lumen endotracheal tube;

$\mathrm{PaCO}_{2}$ : Arterial carbon dioxide tension;

$\mathrm{PaO}_{2}$ : Arterial oxygen tension;

PC: Pressure-controlled;

PEEP: Positive end expiratory pressure;

PFC: Perfluorocarbon;

PIP: Peak inspiratory pressure;

PLV: Partial liquid ventilation. 